\title{
Experimental Investigation on the Deformation, Strength, and Acoustic Emission Characteristics of Sandstone under True Triaxial Compression
}

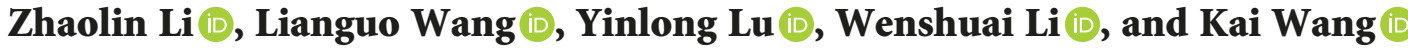 \\ State Key Laboratory for Geomechanics and Deep Underground Engineering, China University of Mining and Technology, \\ Xuzhou, Jiangsu 221116, China \\ Correspondence should be addressed to Lianguo Wang; cumt_lgwang@163.com
}

Received 29 November 2017; Revised 10 March 2018; Accepted 26 March 2018; Published 15 April 2018

Academic Editor: Carlo Santulli

Copyright (c) 2018 Zhaolin Li et al. This is an open access article distributed under the Creative Commons Attribution License, which permits unrestricted use, distribution, and reproduction in any medium, provided the original work is properly cited.

The study of deformation, strength, and other mechanical characteristics of sandstone under true triaxial compression is significant for understanding failure mechanisms in rock and evaluating the stability of underground structures. Conventional and true triaxial compression tests for sandstone are conducted for different stress states in this study using the self-developed true triaxial electrohydraulic servo test system combined with acoustic emission (AE) testing. This study presents an in-depth and systematic investigation of deformation, strength, and AE characteristics. The results show significant differences in deformation, strength, and acoustic emission characteristics for the rock under conventional triaxial and true triaxial compression tests, respectively. The peak strength, axial strain, lateral strain, and incremental strain (in unstable crack growth stage) increase with increasing confining pressure under conventional triaxial compression, and the AE count gradually decreases while shear crack proportion gradually increases, indicating that increasing confining pressure gradually inhibits the shear slip effect along fractures, delays perforation of the rock shear fracture surface, and enhances the ability of the rock to withstand deformation and load. Under true triaxial compression, the peak strength increases and then decreases with increasing intermediate principal stress $\sigma_{2}$ and the axial strain $\varepsilon_{1}$ and lateral strain $\varepsilon_{2}$ gradually decrease; besides, the lateral strain (expansion) of the rock is mainly in the minimum principal stress $\sigma_{3}$ direction, and lateral expansion tends to decrease before increasing. AE events first weaken and then enhance with increasing $\sigma_{2}$, and the proportion of shear cracks increases first and then decreases, indicating that the confining pressure gradually changes from the shear slip effect that controls crack offset to the damage effect that promotes crack tension with increasing $\sigma_{2}$. In addition, the protective effect of confining pressure improves when $\sigma_{3}$ increases.

\section{Introduction}

Rock material is a kind of brittle geological material, which has a complex composition and contains numerous defects, such as joints and cracks. Rock mechanical properties change with variations in external load and environmental factors because of these inherent characteristics. Rock engineering is a fundamental part of construction and is an important support for social development and progress. These projects are all related to research on fundamental rock mechanics problems [1].

The mechanical properties of the rock in Earth's crust are closely related to the $3 \mathrm{D}$ stress state. The deformation, strength, and other mechanical properties can be obtained by studying the deformation and failure of various rocks. Understanding rock failure mechanisms is significant for geotechnical engineering. At present, the study of rock damage in a $3 \mathrm{D}$ stress state is primarily carried out using conventional triaxial tests. Domestic and foreign scholars have studied the mechanical properties of rock under conventional triaxial compression by using conventional testing machines. Karman obtained the earliest stress-strain curves for Carrara marble under different confining pressures on an ordinary testing machine [2]. Fredrich studied the mechanical properties of calcite marble under conventional triaxial compression and examined the effect of 
particle size on the brittle-ductile transition [3]. Yang et al. [4]. carried out conventional triaxial compression tests on sandstones by using a servo testing machine.

However, the influence of the intermediate principal stress is ignored due to the setup of the conventional testing machine. A cylindrical rock sample is subjected to different axial and lateral stresses such that the rock is in an axisymmetric stress state. So, only the strength and deformation for rocks in an axisymmetric stress state are measured, and the general stress states are not represented $\left(\sigma_{1} \neq \sigma_{2} \neq \sigma_{3}\right)$. In a true triaxial compression test, each of the three principle stresses can be independently applied to the sample allowing for the failure mode to be accurately simulated and a more complex stress path to be measured. In recent years, Mogi [5, 6], Haimson et al. [7, 8], and Feng et al. [9] have carried out a large number of experimental studies on rocks using a true triaxial test machine. However, previous studies mainly focus on the effect of the intermediate principal stress on rock strength [10] and the establishment of true triaxial strength criterion to show the effect of the intermediate principal stress on rock strength $[11,12]$. Furthermore, most true triaxial compression experiments examine strength and failure criteria for granite, marble, or other hard rocks, while failure and deformation characteristics for relatively soft rocks, such as sandstone and coal, remain largely unknown.

Underground projects such as roadways are mostly undertaken in sedimentary structures that consist of sandstone-filled channels, and the deformation problems in the roadways are more prominent. Due to the complex microstructure of and numerous defects, its physical and mechanical properties are more sensitive to external loads. Sandstone is one of the most widely distributed rocks in East, South, and Southwest China. With the rapid development of underground construction, understanding the response of sandstone to $3 \mathrm{D}$ stress states is of significance for the construction of underground foundations and roadways. Examining the deformation, strength, and other mechanical properties of sandstone under true triaxial compression can provide reference for the selection of rock mechanics parameters in future geotechnical engineering projects.

The rock damage induced by compression is essentially caused by the continuous development of microcracks, such that the rock fractures. Therefore, the combination of macroscopic mechanical properties such as strength, deformation of the rock, and the development of microcracks in the rock can reveal the cause of the deformation and failure. Acoustic emission (AE) is an effective method to observe the development of microcracks in rock. AE is caused by the generation and expansion of microfractures when rock materials are under an external stress, and $\mathrm{AE}$ is accompanied by elastic wave or stress wave release. AE information reflects the damage and failure state of the rock, which is closely related to the densification of the original internal fissures as well as the generation, expansion, and penetration of the new fissures. The influence of the intermediate principal stress on the development of internal microcracks in rocks can be revealed using AE information. Moradian et al. [13], Yang et al. [14], and Ranjith et al. [15] analyzed the evolution of internal cracks in rocks using AE. However, these studies focused on the evolution of rock fracturing under conventional triaxial compression. Therefore, it is necessary to explore the development of internal microcracks in rock based on $\mathrm{AE}$ to reveal the root cause of rock deformation and failure under true triaxial compression.

In this study, sandstone is subjected to conventional and true triaxial tests with varying stress conditions using the self-developed true triaxial electrohydraulic servo test system. The development of internal cracks within the rock is monitored using an AE monitoring system. The deformation, strength, and $\mathrm{AE}$ characteristics of sandstone under three triaxial stress states are discussed. The effects of different confining pressures under conventional triaxial compression and different stresses in true triaxial compression on the variation of rock deformation, strength parameters, and internal crack development are discussed.

\section{Experimental Methodology}

2.1. True Triaxial Electrohydraulic Servo Test System. The tests presented in this study are carried out using the selfdeveloped true triaxial compression test system (Figure 1). The test system is primarily composed of a maximum principal stress, intermediate principal stress, minimum principal stress $\left(\sigma_{1}, \sigma_{2}, \sigma_{3}\right)$ three-dimensional servo control load system, true triaxial pressure cell, automatic data acquisition system, and $\mathrm{AE}$ monitoring system. The $\sigma_{1}, \sigma_{2}, \sigma_{3}$ three-dimensional servo control load system forms an independent load frame. Piston rods are installed at one end of the three load frames, which is externally connected to the servo valve to produce independent servo loading. The three loading frames are perpendicular to each other. The positions of loading frames $\sigma_{1}$ and $\sigma_{3}$ are fixed, while the third loading frame $\left(\sigma_{2}\right)$ is placed on a horizontal guide rail and has the able to slide along the guide rail to facilitate the operation and placement of the sample. The other end of the two loading frames $\left(\sigma_{2}\right.$ and $\left.\sigma_{3}\right)$ is installed with reaction screws, which have an adjustable length to adapt to different specimen sizes.

Specimens used in this study are cuboids with a size of $50 \times 50 \times 100 \mathrm{~mm}$. The specimen is placed in a cubic pressure chamber composed of a fully rigid structure, which consists of a box-shaped body and a loading plate. In order to avoid deformation of the rock samples leading to mutual extrusion of the loading plate during the test, a gap is left between the vertical and horizontal plates in the traditional true triaxial pressure chamber. This gap causes the uneven stress and strain in the test, resulting in a decrease in peak strength and an abnormal failure pattern in the sample [16]. In order to overcome this defect, the true triaxial pressure cell adopts a rotary interlocking platen design, in which the loading plates on the 6 faces of the sample are arranged in a misplaced method. When the specimen is compressed, the loading plate moves synchronously with the specimen to avoid interference effects in each direction (Figure 1). The relative displacement between the loading plate and the specimen produces a friction force, which negatively influences the test result. To reduce the friction between the 

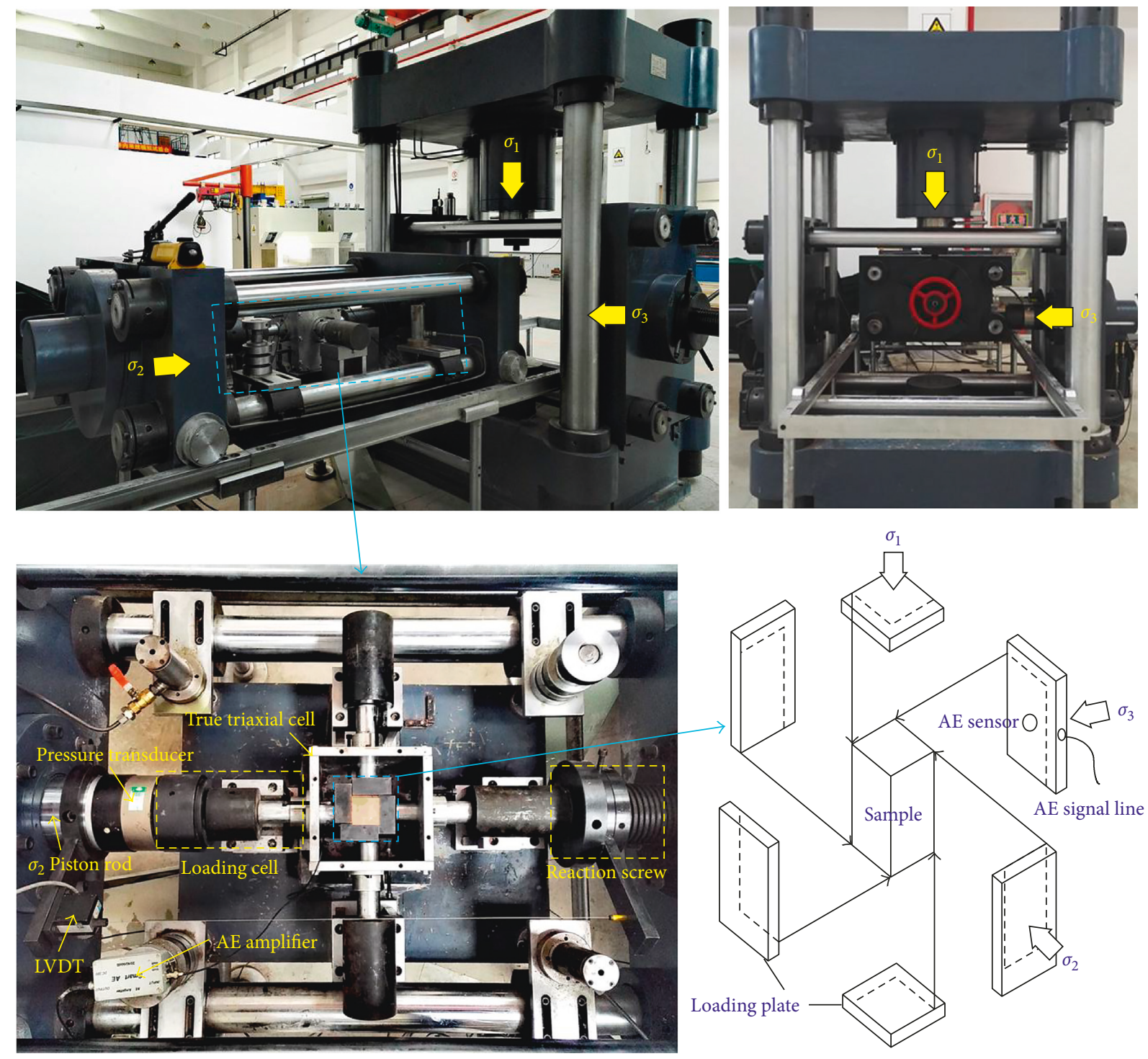

FIGURE 1: True triaxial compression test system.

loading plate and the sample, a $0.5 \mathrm{~mm}$ thick layer of lubricant is applied between the loading plate and the sample surface. The lubricant is composed of a $1: 1$ ratio of stearic acid and Vaseline [17].

A spoke-type pressure sensor with a precision of $0.01 \mathrm{kN}$ is installed between the piston rod and loading block. A rope-type displacement sensor with an accuracy of $0.002 \mathrm{~mm}$ and a measurement range of $1,000 \mathrm{~mm}$ is fixed to the piston rod and reaction force screw. A DS2-8B full information acoustic emission signal analyzer is used to examine the AE activity during tests. The AE system used in this study mainly consists of the AE host, preamplifier, and $\mathrm{AE}$ sensor. The type of the AE sensor is RS-54A, and its monitoring frequency range is $100-900 \mathrm{kHz}$. The $\mathrm{AE}$ sensor is installed in the loading plate of the true triaxial pressure cell (an $8 \mathrm{~mm}$ diameter hole is set in the side of the plate). The AE signal line is drawn out from the hole in the side of the plate, and the probe is in direct contact with the surface of the sandstone to ensure the accuracy of the AE data. The model of AE preamplifier is $20 / 40 / 60 \mathrm{~dB}$ which can provide three different transmission gains; furthermore, it has the advantages of low noise, wide bandwidth, impact resistance, and small volume. During the test, the threshold is set to $40 \mathrm{~dB}$ to avoid the possibility of electronic/environmental noise. The AE signal is amplified by the preamplifier with the gain of $40 \mathrm{~dB}$. The time parameters for $\mathrm{AE}$ waveforms included peak definition time (PDT), hit definition time (HDT), and hit lockout (HLT), which are set to 50, 100, and $100 \mu$ s, respectively.

2.2. Specimen Preparation. Sandstone is selected for examination in this study. Specimens are composed of feldspar and quartz, as well as a small amount of montmorillonite. The sandstone has a medium grain structure with grain size ranging from 0.1 to $0.35 \mathrm{~mm}$ and a relatively dense massive structure. Grains are relatively uniform with an identical macroscopic uniformity and an average density of $2380 \mathrm{~kg} / \mathrm{m}^{3}$. Samples are 
TABLE 1: Tested sandstone specimens and conditions in this research.

\begin{tabular}{|c|c|c|c|c|c|c|}
\hline Loading program & Group & Specimen number & Dimensions $(\mathrm{mm})$ & Quality (g) & $\sigma_{2}(\mathrm{MPa})$ & $\sigma_{3}(\mathrm{MPa})$ \\
\hline \multirow{13}{*}{ СTT } & \multirow{3}{*}{$\mathrm{C} 1$} & $\mathrm{C} 1-1$ & $100.2 \times 50.0 \times 49.8$ & 622.5 & \multirow{3}{*}{10} & \multirow{3}{*}{10} \\
\hline & & $\mathrm{C} 1-2$ & $100.2 \times 49.8 \times 50.1$ & 613.2 & & \\
\hline & & $\mathrm{C} 1-3$ & $100.3 \times 50.1 \times 49.9$ & 612.9 & & \\
\hline & \multirow{3}{*}{$\mathrm{C} 2$} & $\mathrm{C} 2-1$ & $100.0 \times 49.5 \times 50.0$ & 613.0 & \multirow{3}{*}{20} & \multirow{3}{*}{20} \\
\hline & & $\mathrm{C} 2-2$ & $100.5 \times 49.5 \times 50.0$ & 613.5 & & \\
\hline & & $\mathrm{C} 2-3$ & $99.8 \times 50.3 \times 50.3$ & 605.1 & & \\
\hline & \multirow{4}{*}{$\mathrm{C} 3$} & C3-1 & $100.3 \times 50.0 \times 50.1$ & 636.0 & \multirow{3}{*}{30} & \multirow{3}{*}{30} \\
\hline & & $\mathrm{C} 3-2$ & $99.9 \times 50.1 \times 50.2$ & 633.9 & & \\
\hline & & $\mathrm{C} 3-3$ & $99.6 \times 50.3 \times 49.6$ & 602.3 & & \\
\hline & & C4-1 & $99.9 \times 50.1 \times 50.2$ & 625.3 & \multirow{4}{*}{40} & \multirow{4}{*}{40} \\
\hline & \multirow[t]{3}{*}{$\mathrm{C} 4$} & $\mathrm{C} 4-2$ & $99.8 \times 50.2 \times 50.1$ & 629.5 & & \\
\hline & & $\mathrm{C} 4-3$ & $100.2 \times 50.0 \times 49.2$ & 639.7 & & \\
\hline & & $\mathrm{T} 2-1$ & $100.1 \times 50.3 \times 49.8$ & 628.1 & & \\
\hline & \multirow[t]{3}{*}{$\mathrm{T} 2$} & $\mathrm{~T} 2-2$ & $100.4 \times 50.5 \times 50.1$ & 636.0 & \multirow[t]{3}{*}{20} & \multirow[t]{3}{*}{10} \\
\hline & & $\mathrm{T} 2-3$ & $100.3 \times 50.6 \times 50.1$ & 646.6 & & \\
\hline & & T3-1 & $100.4 \times 49.9 \times 50.3$ & 630.5 & & \\
\hline & \multirow[t]{3}{*}{$\mathrm{T} 3$} & T3-2 & $100.0 \times 50.2 \times 50.1$ & 650.0 & \multirow[t]{3}{*}{30} & \multirow[t]{3}{*}{10} \\
\hline & & $\mathrm{T} 3-3$ & $99.8 \times 50.4 \times 50.5$ & 624.7 & & \\
\hline & & T4-1 & $100.4 \times 49.6 \times 49.6$ & 618.8 & & \\
\hline \multirow[t]{13}{*}{$\operatorname{TTT}\left(\sigma_{3}=10 \mathrm{MPa}\right)$} & \multirow[t]{3}{*}{$\mathrm{T} 4$} & T4-2 & $100.3 \times 49.7 \times 49.9$ & 626.7 & \multirow[t]{3}{*}{40} & \multirow[t]{3}{*}{10} \\
\hline & & T4-3 & $100.1 \times 50.4 \times 50.6$ & 607.1 & & \\
\hline & & T5-1 & $100.1 \times 50.1 \times 49.9$ & 615.6 & & \\
\hline & \multirow[t]{3}{*}{$\mathrm{T} 5$} & T5-2 & $99.9 \times 49.5 \times 50.2$ & 610.8 & \multirow[t]{3}{*}{50} & \multirow[t]{3}{*}{10} \\
\hline & & $\mathrm{T} 5-3$ & $100.2 \times 50.1 \times 49.9$ & 614.5 & & \\
\hline & & T6-1 & $99.7 \times 49.7 \times 50.3$ & 610.4 & & \\
\hline & T6 & T6-2 & $99.8 \times 49.9 \times 50.2$ & 606.3 & 60 & 10 \\
\hline & & T6-3 & $100.1 \times 49.8 \times 50.2$ & 595.7 & & \\
\hline & & T7-1 & $100.3 \times 49.9 \times 50.2$ & 630.5 & & \\
\hline & $\mathrm{T} 7$ & T7-2 & $99.8 \times 50.4 \times 50.5$ & 624.2 & 30 & 20 \\
\hline & & T7-3 & $99.9 \times 49.5 \times 50.2$ & 612.3 & & \\
\hline & & T8-1 & $100.4 \times 49.8 \times 50.2$ & 599.8 & & \\
\hline & $\mathrm{T} 8$ & T8-2 & $100.1 \times 50.4 \times 50.3$ & 603.1 & 40 & 20 \\
\hline & & T8-3 & $99.7 \times 50.1 \times 50.3$ & 615.4 & & \\
\hline $\operatorname{TTT}\left(\sigma_{3}=20 \mathrm{MPa}\right)$ & & T9-1 & $100.3 \times 49.7 \times 49.9$ & 621.7 & & \\
\hline & T9 & T9-2 & $100.1 \times 50.1 \times 49.9$ & 615.6 & 50 & 20 \\
\hline & & T9-3 & $100.0 \times 49.7 \times 50.1$ & 630.1 & & \\
\hline & & $\mathrm{T} 10-1$ & $99.8 \times 49.9 \times 50.4$ & 626.3 & & \\
\hline & $\mathrm{T} 10$ & $\mathrm{~T} 10-2$ & $100.2 \times 50.1 \times 49.9$ & 624.6 & 60 & 20 \\
\hline & & $\mathrm{T} 10-3$ & $100.3 \times 49.8 \times 49.9$ & 621.7 & & \\
\hline
\end{tabular}

$50 \times 50 \times 100 \mathrm{~mm}$ in size, and the end faces are carefully polished. Detailed sample information is given in Table 1 .

2.3. Testing Procedure. In order to study the mechanical properties and AE characteristics of rock under true triaxial compression, the difference between the true triaxial test (TTT) and conventional triaxial test (CTT) is compared and the influence of different triaxial stresses on rock mechanical properties and AE characteristics is analyzed. The test setup is shown in Figure 2.

2.3.1. CTT. Pressure is applied to the specimen at a rate of $0.2 \mathrm{MPa} / \mathrm{s}$ up to a predetermined confining pressure (set values of $\sigma_{2}$ and $\sigma_{3}$ ), while the specimen is maintained in a hydrostatic pressure state $(o a)$; then, with constant confining pressure, the axial stress is applied to the specimen at a loading rate of $0.002 \mathrm{~mm} / \mathrm{s}$, until the specimen failed $(a b)$.
2.3.2. TTT. Pressure is applied to the specimen at a rate of $0.2 \mathrm{MPa} / \mathrm{s}$ up to a predetermined confining pressure (set value of $\sigma_{3}$ ), while the specimen is maintained in a hydrostatic pressure state $\left(o a, o a^{\prime}\right)$; then, with constant $\sigma_{3}$, the values of $\sigma_{1}$ and $\sigma_{2}$ are continuously increased to the set value of $\sigma_{2}\left(a b, a^{\prime} b^{\prime}\right)$ at the same rate. Afterwards with constant $\sigma_{2}$ and $\sigma_{3}$, the axial stress is applied to the specimen at a loading rate of $0.002 \mathrm{~mm} / \mathrm{s}$, until the specimen failed $\left(b c, b^{\prime} c^{\prime}\right)$.

Since the test discreteness is considered in this study, each test is repeated 2 times. The specific test scheme is shown in Table 1.

\section{Strength and Deformation Behavior}

3.1. Strength and Criterion Verification. In order to analyze the strength characteristics of sandstone under conventional triaxial and true triaxial compression and to further verify the accuracy of the test results for the triaxial test system, 


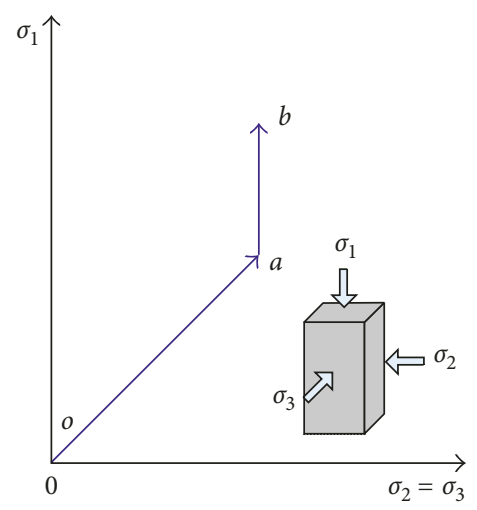

(a)

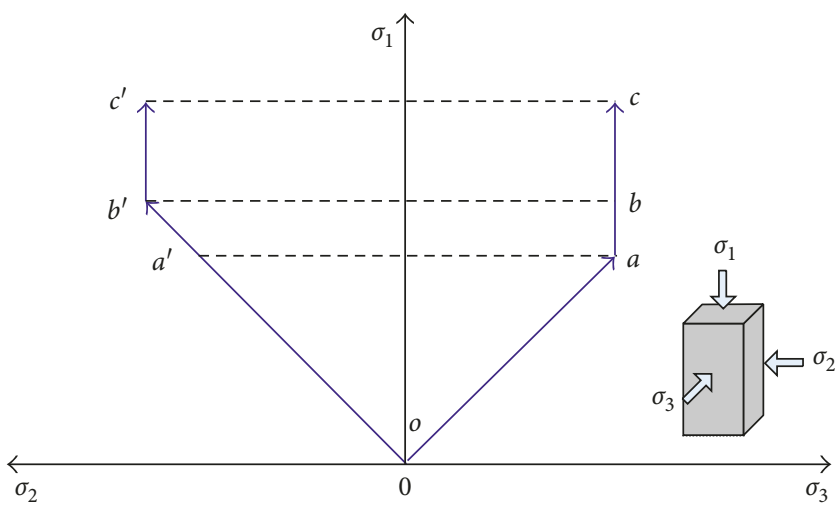

(b)

Figure 2: The two different loading programs: (a) CTT; (b) TTT.

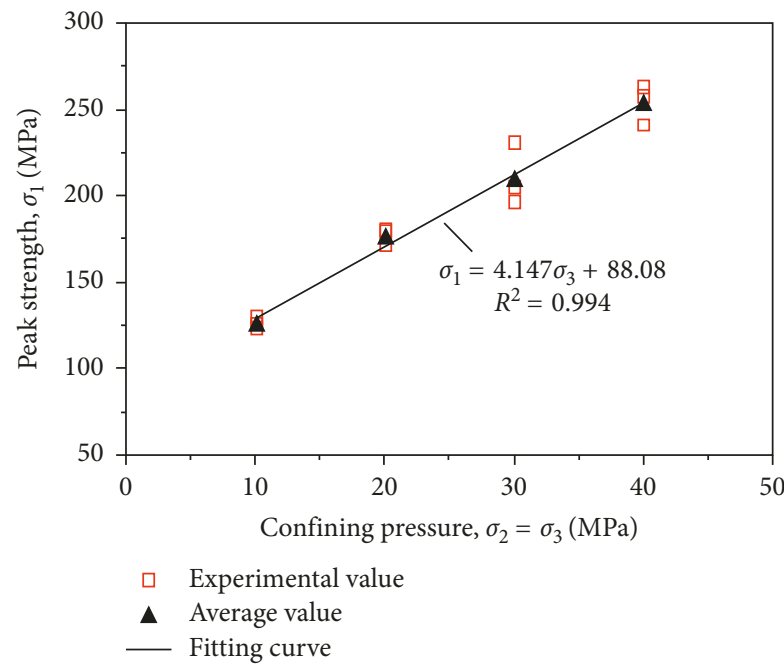

FIGURE 3: Peak strength $\sigma_{1}$ as a function of the minimum principal stress $\sigma_{3}$ under conventional triaxial stress and the best-fit linear function strength criterion (Mohr-Coulomb) for sandstone specimens.

rock strength and the strength-fitting curve under the two loading conditions are obtained (Figures 3 and 4). The peak strength increases linearly with increasing confining pressure under conventional triaxial compression (Figure 3). The Mohr-Coulomb criterion is used to fit the relationship between the confining pressure and rock strength under the conventional triaxial compression. The fitting correlation coefficient is $R^{2}=0.994$, which reflects the relationship between rock strength and varying confining pressure under conventional triaxial compression.

Because the influence of the intermediate principal stress on the rock strength is not considered in the MohrCoulomb criterion, the Mohr-Coulomb criterion is only applicable to the special case in which $\sigma_{2}=\sigma_{3}$, and it cannot accurately reflect the strength characteristics of the rock. Domestic and foreign scholars have come to realize the significance of the intermediate principal stress on ultimate compressive strength. Mogi [5, 6], Al-Ajmi and Zimmerman

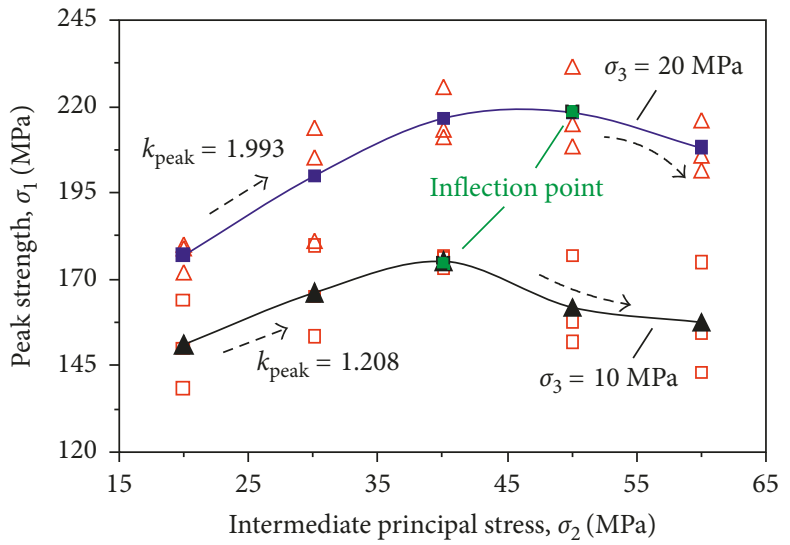

(a)

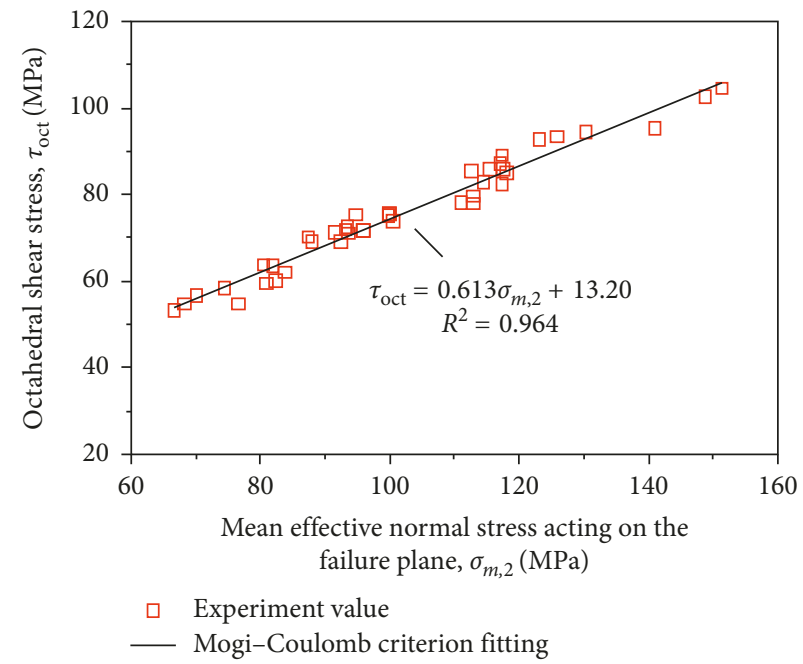

(b)

FIgURE 4: True triaxial strength for sandstone: (a) variation of peak compressive stress $\sigma_{1}$ as a function of $\sigma_{2}$ for the constant values of $\sigma_{3}=10 \mathrm{MPa}$ and $\sigma_{3}=20 \mathrm{MPa} ; k_{\text {peak }}$ represents the slope of the peak strength with increasing $\sigma_{2}$; (b) the best-fit linear function true triaxial strength criterion (Mogi-Coulomb Criterion) based on all experimental results in terms of $\tau_{\mathrm{oct}}$ versus $\sigma_{m, 2}$. 
[18], Oku et al. [19], Lee and Haimson [20], and Chang and Haimson [21] considered that a true triaxial failure criterion can be expressed as a linear function (the MogiCoulomb criterion) between octahedral shear stress $\tau_{\text {oct }}$ and the average effective normal stress acting on the shear plane $\sigma_{m, 2}$ :

$$
\begin{aligned}
\tau_{\mathrm{oct}} & =a+b \sigma_{m, 2}, \\
\tau_{\mathrm{oct}} & =\frac{1}{3} \sqrt{\left(\sigma_{1}-\sigma_{2}\right)^{2}+\left(\sigma_{2}-\sigma_{3}\right)^{2}+\left(\sigma_{1}-\sigma_{3}\right)^{2}}, \\
\sigma_{m, 2} & =\frac{\sigma_{1}+\sigma_{3}}{2},
\end{aligned}
$$

where $\tau_{\text {oct }}$ and $\sigma_{m, 2}$ are the octahedral shear stress and the average effective normal stress on the shear plane, respectively, and $a$ is the intercept of Mogi's linear criterion fitting straight line and $\tau_{\text {oct }}$ axis, and $b$ is the slope of straight line.

By comparing the Mohr-Coulomb criterion and MogiCoulomb criterion, the relationship between them is concluded:

$$
\begin{aligned}
& a=\frac{2 \sqrt{2}}{3} c \cos \varphi, \\
& b=\frac{2 \sqrt{2}}{3} \sin \varphi .
\end{aligned}
$$

According to the suggestions from ISRM, the MogiCoulomb criterion is used to fit the strength of the rock (including conventional and true triaxial strength) (Figure 4(b)). According to the fitting results, the Mogi-Coulomb criterion $\left(R^{2}=0.964\right)$ reflects the strength characteristics of the rock under true triaxial loading conditions relatively well and is consistent with the test results of Mogi, Haimson, and Chang. These results are further verified by the reliability and accuracy of the experimental system used in this study.

The values of $c$ and $\varphi$ of the sandstone under two different strength criteria are shown in Table 2 and are obtained by combining (1)-(4) according to the parameters in the fitting equations in Figures 3 and 4(b). The fitting coefficient of the two strength criteria is high. Therefore, the values of $c$ and $\varphi$ of the sandstone are relatively close to each other. The Mogi-Coulomb criterion applies to both the conventional and true triaxial test and is more universal. The Mohr-Coulomb criterion is a special case of the Mogi-Coulomb criterion.

The strength characteristics of rock under true triaxial compression are shown in Figure 4(a), and the variation is different from that of conventional triaxial condition. The peak rock strength increases and then decreases with increasing $\sigma_{2}$ under true triaxial loading. When $\sigma_{3}=10 \mathrm{MPa}$ and $20 \mathrm{MPa}$, the peak rock strength first increases to the maximum and then gradually decreases with increasing $\sigma_{2}$. Inflection points are located at $40 \mathrm{MPa}$ and $50 \mathrm{MPa}$, respectively. The ascending segment tends to increase linearly with increasing $\sigma_{2}$, and the slopes of the peak strength are 1.208 and 1.993, indicating that improving $\sigma_{3}$ has a more significant protective effect on the rock.
TABLE 2: Fitting results and parameter values of two strength criteria of sandstone.

\begin{tabular}{lcccc}
\hline Group & Criterion & $c(\mathrm{MPa})$ & $\varphi\left(^{\circ}\right)$ & $R^{2}$ \\
\hline CTT & Mohr-Coulomb & 21.6 & 37.7 & 0.994 \\
TTT & Mogi-Coulomb & 18.4 & 40.5 & 0.964 \\
\hline
\end{tabular}

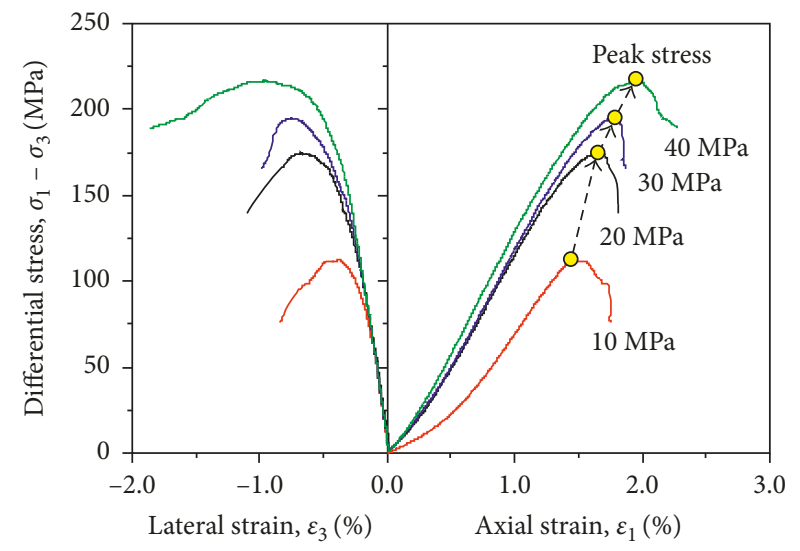

FIgURE 5: Stress-strain curves for sandstone from conventional triaxial compression experiments.

3.2. Stress-Strain Curve. In this study, the stress-strain curves under conventional and true triaxial compression with different confining pressure conditions are shown in Figures 5 and 6, where the yellow origin represents the peak strength of the rock. Rock stress-strain characteristics for four confining pressures under conventional triaxial compression are similar (Figure 5). The steepness of the curve in the elastic deformation stage is greatly affected by the confining pressure. The larger the confining pressure, the steeper the curve is, which indicates that the elastic modulus of the sandstone increases with increasing of confining pressure. The difference in steepness of the lateral curve is not obvious, which shows that the effect of confining pressure on the steepness of the lateral deformation of sandstone is small. The axial strain, lateral strain, and peak strength of the rock increase with increasing confining pressure, which shows that the increase in the conventional triaxial confining pressure improves the ability of the rock to withstand deformation and loading in both the axial and lateral directions.

Figures 6(a)-6(d), respectively, show the relationships between the differential stress $\left(\sigma_{1}-\sigma_{3}\right)$ and principal strain $\left(\varepsilon_{1}, \varepsilon_{2}\right.$, and $\left.\varepsilon_{3}\right)$ as well as volumetric strain $\left(\varepsilon_{\mathrm{V}}\right)$ under true triaxial compression. Considering that different intermediate principal stresses under true triaxial compression are taken, the test process is divided into one section with a loading by force $\left(o \rightarrow a\left(a^{\prime}\right) \rightarrow b\left(b^{\prime}\right)\right)$ and other section with a loading by displacement $\left(b\left(b^{\prime}\right) \rightarrow c\left(c^{\prime}\right)\right)$. To facilitate the analysis, the rock's stress-strain characteristics are only analyzed for the loading by the displacement section.

The condition of the rock in the initial compaction stage is not obvious due to the effect of loading (Figure 6(a)). The rock enters the elastic stage quickly, and the axial curve is 


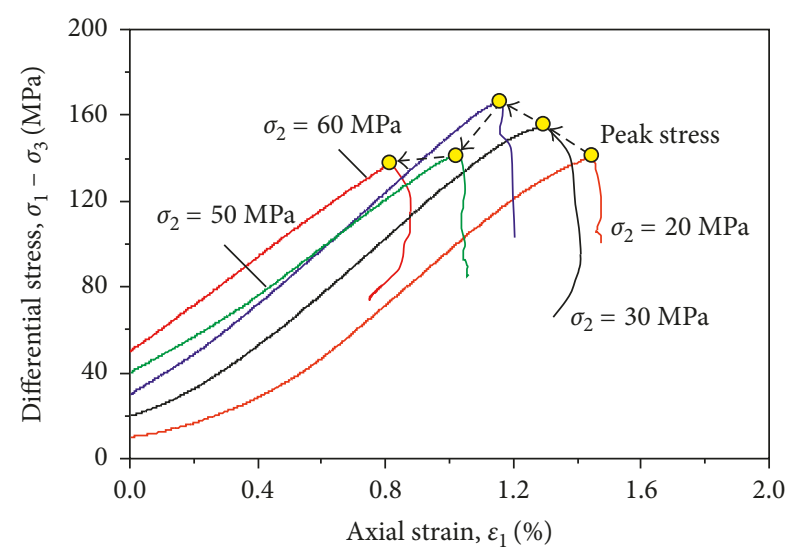

(a)

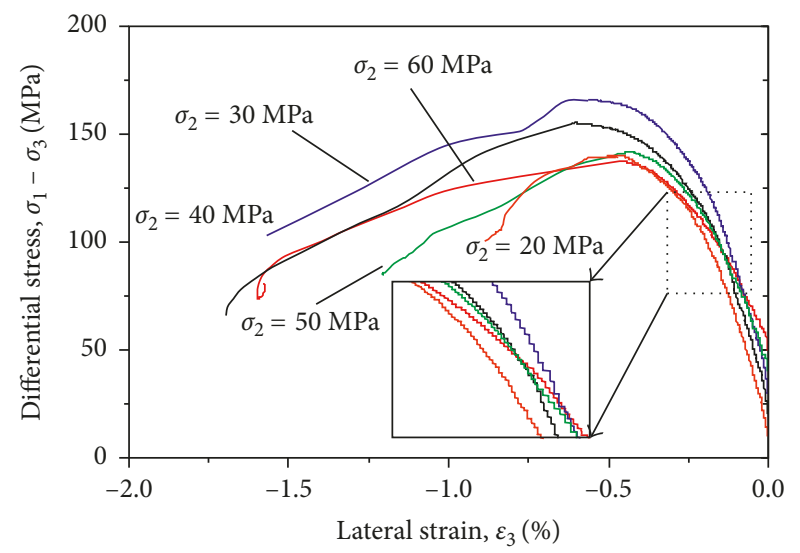

(c)

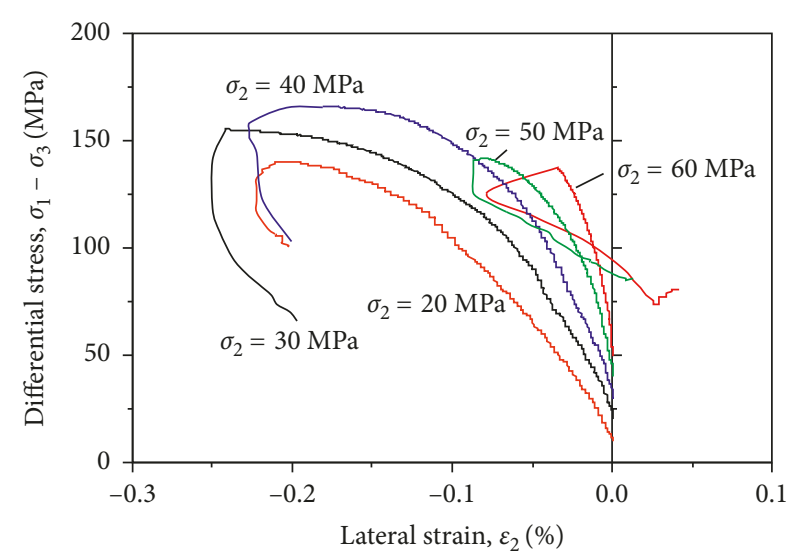

(b)

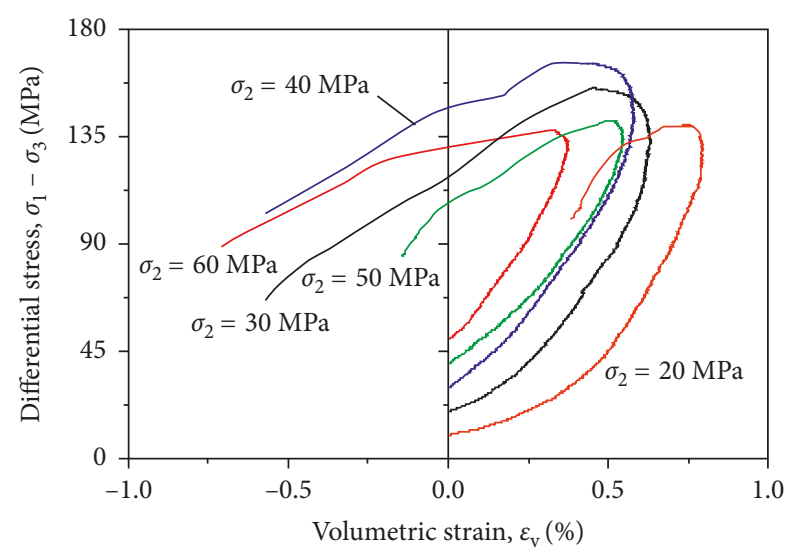

(d)

FiguRE 6: Differential stress $\left(\sigma_{1}-\sigma_{3}\right)$-strain relations for sandstone under true triaxial compression conditions with a constant $\sigma_{3}$ of $10 \mathrm{MPa}$ : (a) differential stress $\left(\sigma_{1}-\sigma_{3}\right)$-axial strain $\left(\varepsilon_{1}\right)$; (b) differential stress $\left(\sigma_{1}-\sigma_{3}\right)$-lateral strain $\left(\varepsilon_{2}\right)$; (c) differential stress $\left(\sigma_{1}-\sigma_{3}\right)$-lateral strain $\left(\varepsilon_{2}\right)$; (d) differential stress $\left(\sigma_{1}-\sigma_{3}\right)$-volumetric strain $\left(\varepsilon_{2}\right)$.

linear under different $\sigma_{2}$ conditions. The steepness of the axial curve is effected by $\sigma_{2}$. The steepness of the axial curve increases and gradually decreases with increasing $\sigma_{2}$. The variation law is different from that of conventional triaxial compression. The elastic modulus gradually increases and then decreases with increasing $\sigma_{2}$, and the variation law is consistent with peak strength. The strain during loading by displacement gradually reduces with increasing $\sigma_{2}$, and the lateral expansion of the rock gradually plays a more dominant role.

The strain curve in the direction of intermediate principal stress gradually steepens with increasing $\sigma_{2}$ (Figure 6(b)). The increase of $\sigma_{2}$ limits the deformation (expansion) in the $\sigma_{2}$ direction. After the peak stress is reached, the rock experiences compression in the intermediate principal stress direction especially when $\sigma_{2}$ equals $50 \mathrm{MPa}$ or $60 \mathrm{MPa}$, indicating that brittle failure of the rock occurs under such intermediate principal stress conditions, and the rock extends rapidly along the minimum principal stress direction, which leads to the rapidly compressed in the intermediate principal stress direction after the peak.

The strain curve in the direction of minimum principal stress steepens and gradually shallows with increasing $\sigma_{2}$
(Figure 6(c)). The lateral expansion of the rock mainly in the direction of the minimum principal stress is due to the increase of $\sigma_{2}$. Because $\sigma_{2}>\sigma_{3}$, the expansion of the rock in the direction of minimum principal stress is promoted by increasing $\sigma_{2}$. At the same time, the lateral expansion of rock could be limited by $\sigma_{2}$, which can be regarded as the confining pressure. Results show that when $\sigma_{2}$ is $20 \mathrm{MPa} \sim 40 \mathrm{MPa}$, the increase of $\sigma_{2}$ plays a protective role for the rock and limits deformation in the direction of $\sigma_{3}$ (lateral restraint effect). When $\sigma_{2}$ is $50 \mathrm{MPa}$ or $60 \mathrm{MPa}$, the increase of $\sigma_{2}$ plays a damaging role for the rock and accelerates deformation in the direction of $\sigma_{3}$ (damage effect).

In Figure 6(d), the change in rock volumetric strain $\left(\varepsilon_{\mathrm{V}}\right)$ is shown. $\varepsilon_{\mathrm{V}}$ first increases and then decreases, showing that the rock undergoes gradual compression first, and then begins to expand with increasing differential stress. The inflection point of $\varepsilon_{\mathrm{V}}$ is the point where rock volume stops compression and begins to expansion. The inflection point of volumetric strain is more easily reached with the increasing $\sigma_{2}$.

The stress-strain curve of the rock under at $\sigma_{3}=20 \mathrm{MPa}$ is similar to that of $\sigma_{3}=10 \mathrm{MPa}$ (Figure 7). The rock axial strain curve is steeper, which indicates that the elastic 


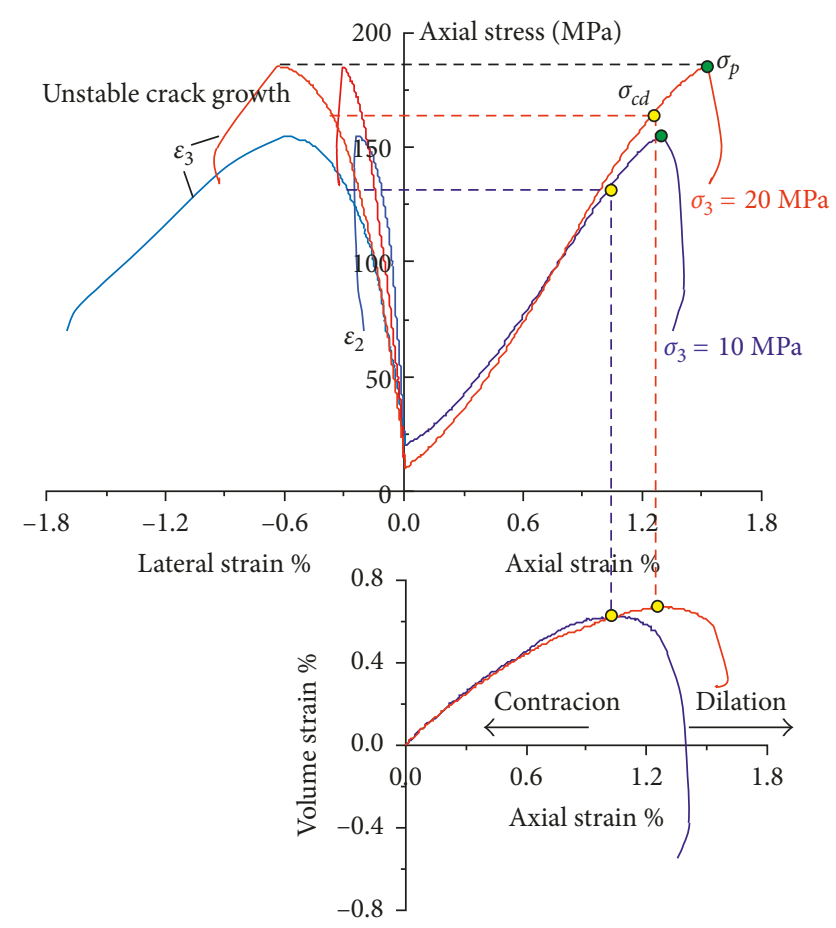

FIGURE 7: Stress-strain curve of rock at varying $\sigma_{3}\left(\sigma_{2}=30 \mathrm{MPa}\right)$.

modulus of the rock increases. The peak strength, axial strain, and lateral strain of the rock increase with increasing $\sigma_{3}$, and the strain corresponding to the inflection point of $\varepsilon_{V}$ greatly improved. The increase of $\sigma_{3}$ enhances the ability of the rock to bear stress and improves the carrying capacity of the rock.

The variation of elastic modulus under conventional triaxial and true triaxial compression is shown in Figure 8. The elastic modulus increases with increasing confining pressure under conventional triaxial compression (Figure $8(\mathrm{a})$ ). The variation is similar to that of strength, which shows that there are microcracks in the rock and the confining pressure closes the cracks to some extent, causing some slippage between cracks. If the confining pressure increases, cracks would close more fully, and slippage between the cracks decreases. The increase of confining pressure makes slip along the cracks reduce due to the inhibition of the frictional force. Therefore, the axial deformation of the specimen decreases, and the elastic modulus of the rock increases.

The elastic modulus of the rock first increases and then decreases with increasing $\sigma_{2}$ under true triaxial compression, in which $\sigma_{3}$ is 10 and $20 \mathrm{MPa}$, and the values of the two peak points are both $\sigma_{2}=40 \mathrm{MPa}$ (Figure $8(\mathrm{~b})$ ). When $\sigma_{2}$ is $20 \sim 40 \mathrm{MPa}$, the number of slippage cracks in the rock is effectively reduced by improving $\sigma_{2}$, and slip along the microcracks is inhibited, which leads to an increased elastic modulus. The effect of confining pressure is similar to that of conventional triaxial compression. When $\sigma_{2}$ exceeds $40 \mathrm{MPa}$, the confining pressure promotes the expansion of microcracks in the rock, and the elastic modulus gradually decreases (Figure 6(c)). By comparing the variation laws of elastic modulus when $\sigma_{3}$ is $10 \mathrm{MPa}$ and $20 \mathrm{MPa}$, it is apparent that the latter elastic modulus is larger, indicating that

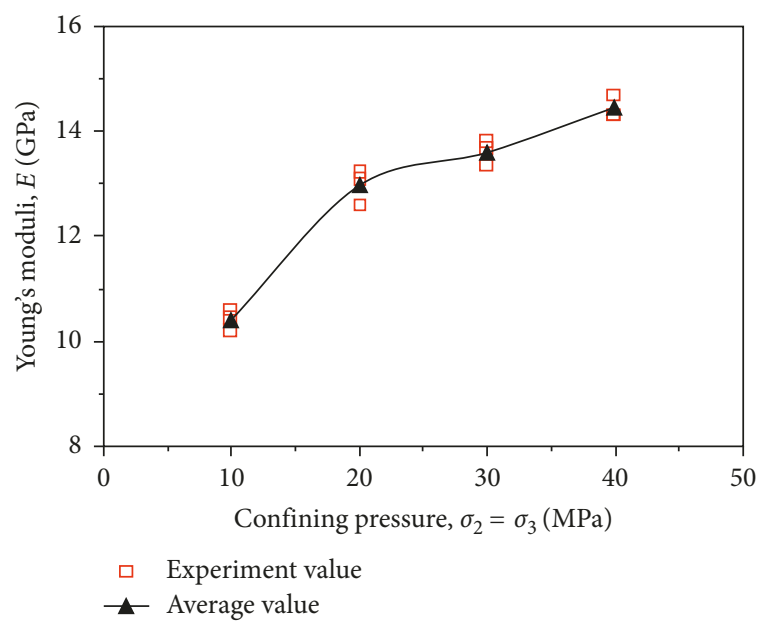

(a)

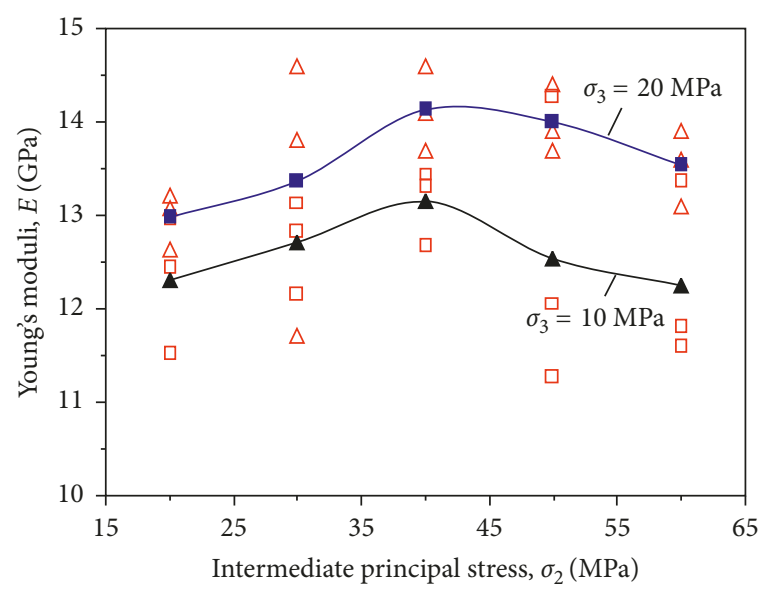

(b)

FIGURE 8: Influence of the confining pressure on Young's modulus of sandstone: (a) CTT; (b) TTT.

the increase of $\sigma_{3}$ makes the cracks close more fully and reduces slip. When $\sigma_{2}$ is $40 \sim 60 \mathrm{MPa}$, the decrease of the latter elastic modulus is slower than the former, which indicates that the increase of $\sigma_{3}$, to some extent, slows down the variation trend of "first increase and then decrease" under true triaxial compression and plays a protective role to the rock.

\subsection{Strength and Deformation Characteristic in Unstable} Crack Growth Stage. The deformation properties of rock are closely related to the growth and development of internal cracks. The rock failure process is associated with the closure, fracture initiation, expansion, and interactive perforation of cracks. The failure process is divided into the following stages [22]: (1) microcrack closure compaction stage; (2) elastic deformation stage; (3) stable crack growth stage; (4) unstable crack growth stage; (5) postpeaking stage. When the axial stress gradually increases to the rock damage stress $\sigma_{c d}$, the stress-strain curve enters the unstable crack growth stage, marking the beginning of shear and expansion of the rock sample. In this stage, the cracks are unstable. 


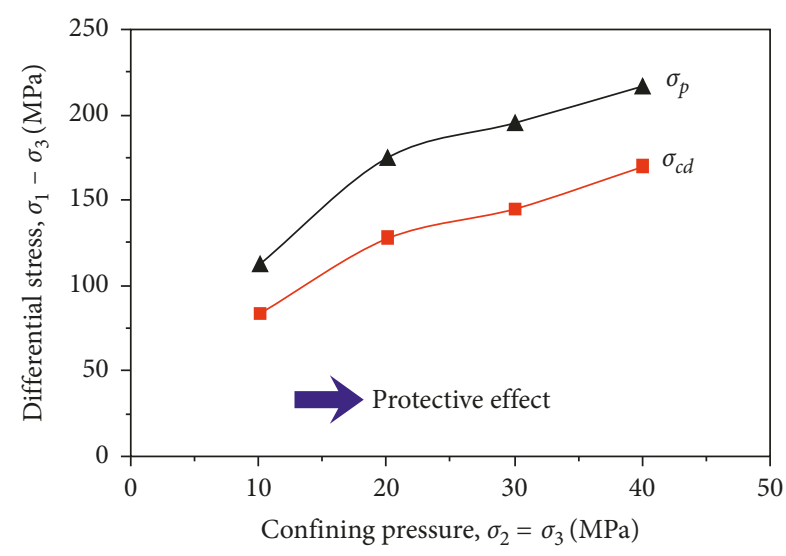

(a)

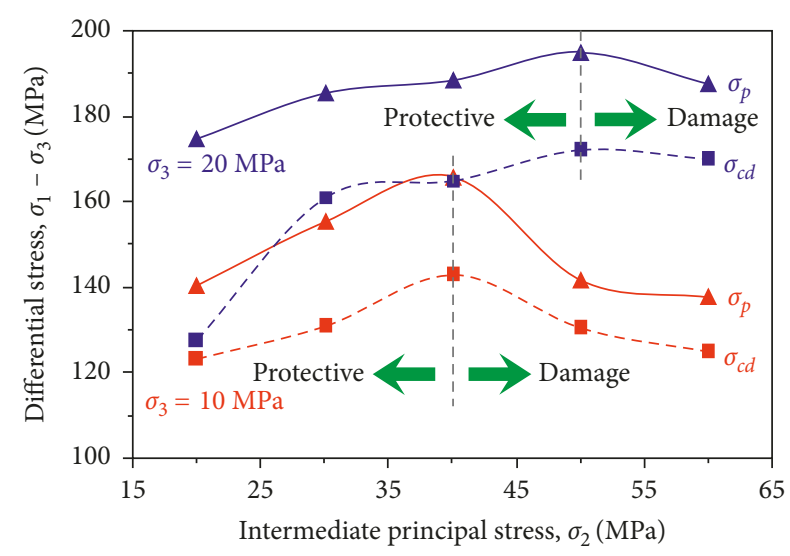

(b)

FIGURE 9: Variation rule of rock damage strength and peak strength under conventional triaxial and true triaxial conditions.

Even if the rock is no longer loaded, the internal cracks in the rock specimen cannot hold stable for a significant amount of time and continue to expand over time. Therefore, the damage stress is also called the long-term strength of the rock. Examination of rock deformation, strength, and crack development in this stage is of great significance to understanding its failure mechanism. This study focuses on the analysis of rock strength, deformation, and acoustic emission characteristics in this stage.

The variation rule of damage strength and peak strength under conventional triaxial and true triaxial compression is shown in Figure 9. Damage strength $\sigma_{c d}$ and peak strength $\sigma_{p}$ of the rock under conventional triaxial compression increase with increasing confining pressure (Figure 9(a)). Because there are microcracks in the rock, development of cracks is effectively prevented, and the expansion of internal cracks of the rock is restrained laterally by improving confining pressure.

Variation of damage strength $\sigma_{c d}$ and peak strength $\sigma_{p}$ for rocks under true triaxial compression $\left(\sigma_{3}=10 \mathrm{MPa}\right.$ and $20 \mathrm{MPa})$ is different from rocks under conventional triaxial compression (Figure 9(b)). Damage strength $\sigma_{c d}$ and peak strength $\sigma_{p}$ both increase first and then decrease. When $\sigma_{3}$ is $10 \mathrm{MPa}$, the damage stress $\sigma_{c d}$ and peak strength $\sigma_{p}$ show an obvious trend of "first increasing and then decreasing," and the confining pressure constrains the expansion of internal cracks when $\sigma_{2}$ is small. While the lateral restraint gradually transforms into a damaging force on the rock with increasing $\sigma_{2}$, the expansion of internal cracks in the rock is promoted, leading to decreasing $\sigma_{c d}$ and $\sigma_{p}$. By comparing variations in damage and peak strength under true triaxial compression, it is apparent that $\sigma_{3}$ equal to $10 \mathrm{MPa}$ and $20 \mathrm{MPa}$ corresponds to $\sigma_{2}$ equal to $40 \mathrm{MPa}$ and $50 \mathrm{MPa}$, respectively. The latter values of $\sigma_{c d}$ and $\sigma_{p}$ are higher and vary more gradually than the former values. In particular, the values of $\sigma_{c d}$ and $\sigma_{p}$ decrease when the former $\sigma_{2}$ exceeds $40 \mathrm{MPa}$, while the values of $\sigma_{c d}$ and $\sigma_{p}$ reduce slightly when the latter $\sigma_{2}$ exceeds $50 \mathrm{MPa}$, indicating that the damage effect of the latter confining pressure is significantly weakened, and improving $\sigma_{3}$ limits the development of internal cracks.

The strain characteristics corresponding to damage and peak stress of the rock under conventional triaxial compression are shown in Figure 10. The axial strain and lateral strain corresponding to damage and peak stress of the rock under conventional triaxial compression vary linearly with confining pressure, all of which increase with increasing confining pressure. Volumetric strain fluctuates greatly. The lateral strain of the peak point $\varepsilon_{p}^{3}$ increases more quickly than the axial strain $\varepsilon_{p}^{1}$ with increasing confining pressure, which indicates that the lateral strain dominates during the unstable crack growth stage and the admission value of lateral expansion increases. At the same time, the volumetric strain increment of the rock $\Delta \varepsilon_{v}\left(=\varepsilon_{p}^{v}-\varepsilon_{c d}^{v}\right)$ in this stage increases with increasing confining pressure, which indicates that the ability of the rock to withstand deformation increases gradually due to increasing confining pressure under the conventional triaxial compression.

Incremental strain variation in the unstable crack growth stage under the conventional triaxial compression is shown in Figure 11. The axial strain increment $\Delta \varepsilon_{1}$ increases slightly with increasing confining pressure in this stage, while the lateral strain $\Delta \varepsilon_{3}$ increases quickly. The volumetric strain increment $\Delta \varepsilon_{\mathrm{V}}$ increases quickly with increasing confining pressure due to $\Delta \varepsilon_{v}=\Delta \varepsilon_{1}+2 \Delta \varepsilon_{3}$, which indicates that the lateral expansion of the rock in the unstable crack growth stage under the conventional triaxial compression is obvious, and the ability to withstand lateral deformation increases significantly due to increasing confining pressure.

The strain characteristics of rock damage point and peak point under true triaxial condition are shown in Figure 12. Because the deformation characteristics of the rock in the loading segment by displacement are only analyzed, the values of $\sigma_{3}$ and $\sigma_{2}$ are $20 \mathrm{MPa}$ under the conventional triaxial compression in this study, and the strain law is not discussed because of its abnormality. Axial strains of the damage point and the peak point under true triaxial compression decrease with increasing $\sigma_{2}$. Variation is similar when $\sigma_{3}$ is 10 and $20 \mathrm{MPa}$, and the latter axial strains of the damage point and peak point $\varepsilon_{c d}^{1}$ and $\varepsilon_{p}^{1}$ are higher than the former ones. The lateral strains $\varepsilon_{c d}^{2}$ and $\varepsilon_{p}^{2}$ in the direction of $\sigma_{2}$ decrease gradually with increasing $\sigma_{2}$. Deformation 


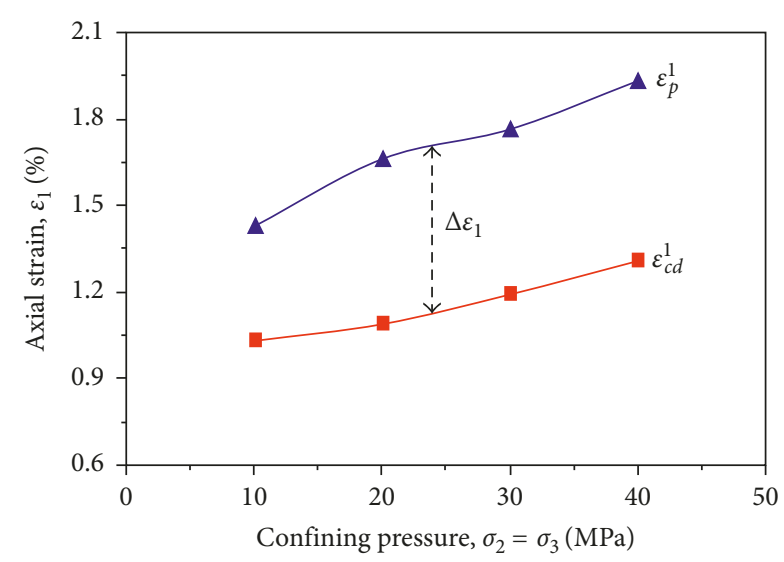

(a)

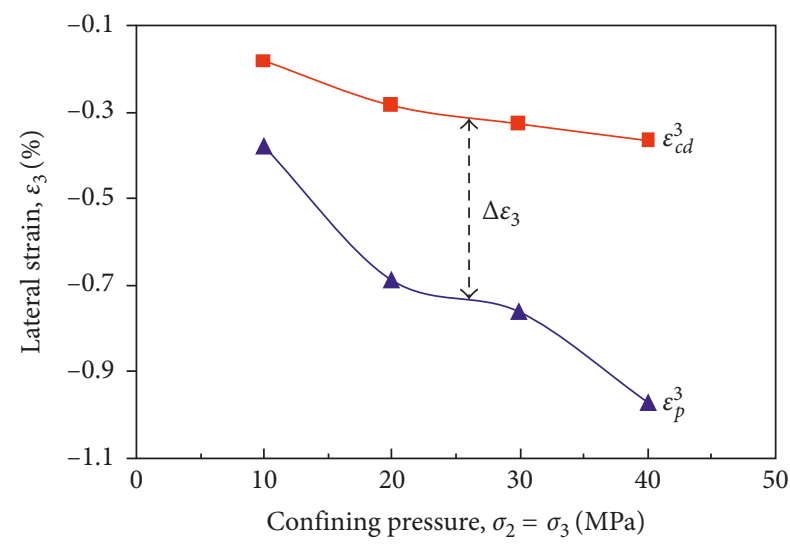

(b)

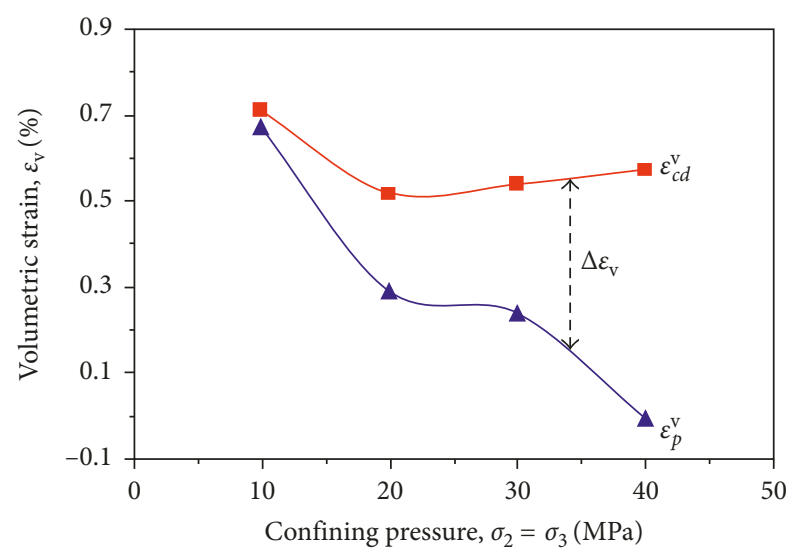

(c)

FIGURE 10: Influence of the confining pressure on strain corresponding to each characteristic stress under conventional triaxial compression experiments: (a) axial strain; (b) lateral strain; (c) volumetric strain.

in the rock reflects expansion in the $\sigma_{2}$ direction, and the expansion is limited by an increasing $\sigma_{2}$. The restriction is more pronounced when $\sigma_{3}$ equals $20 \mathrm{MPa}$ (Figure 12(b)). The change laws of the two kinds of conditions where $\sigma_{3}$ is 10 or $20 \mathrm{MPa}$ are different in the direction of $\sigma_{3}$ (Figure $12(\mathrm{c})$ ). When $\sigma_{3}$ is $10 \mathrm{MPa}$, the lateral strain in the minimum principal stress direction $\varepsilon_{p}^{3}$ (expansion) of the rock peak

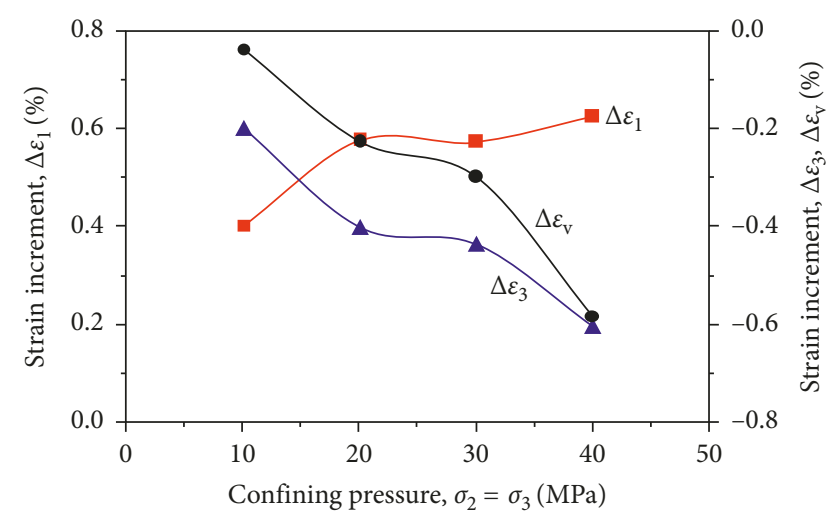

FIgURE 11: Variation in strain increment in the unstable crack growth stage under the conventional triaxial compression.

point first increases and then decreases with increasing $\sigma_{2}$. When $\sigma_{2}$ is $50 \mathrm{MPa}$ or $60 \mathrm{MPa}$, the lateral strain exhibits a sharp decrease, indicating that the rock reaches the peak point at a fast speed and its ability to withstand deformation is significantly weakened. When $\sigma_{3}$ is $20 \mathrm{MPa}$, the lateral strain $\varepsilon_{p}^{3}$ (expansion) of the rock peak point first increases and then decreases with increasing $\sigma_{2}$. Here, while $\sigma_{2}$ is $60 \mathrm{MPa}$, the lateral strain decreases slightly, indicating that the lateral strain $\varepsilon_{p}^{3}$ of the peak point reduces the ability to withstand lateral strain. However, due to increasing $\sigma_{3}$, the rock suffers only a slight decrease in lateral deformation capacity. The law of rock volumetric strain is similar to that in the minimum principal stress direction (Figure 12(d)). When $\sigma_{3}$ is $10 \mathrm{MPa}$, the peak volumetric strain $\varepsilon_{p}^{\mathrm{v}}$ first increases and then decreases with increasing $\sigma_{2}$. When $\sigma_{3}$ is $20 \mathrm{MPa}$, the peak volumetric strain $\varepsilon_{p}^{\mathrm{v}}$ slightly decreases with increasing $\sigma_{2}$, whose value is higher than the former one $\left(\sigma_{3}=10 \mathrm{MPa}\right)$, which indicates that the rock's ability to support expansion and deformation could be improved by increasing $\sigma_{3}$.

The variation in strain increment in the unstable stage under true triaxial compression is shown in Figure 13. The axial strain increment $\Delta \varepsilon_{1}$ and lateral strain increment $\Delta \varepsilon_{2}$ in the intermediate principal stress direction in this stage are similar when $\sigma_{3}$ is 10 and $20 \mathrm{MPa}$ and decreases with increasing $\sigma_{2}$. The difference in strain increment $\Delta \varepsilon_{3}$ in the direction of the minimum principal stress is large. Strain increments first increase and then decrease, but the former decreases significantly when $\sigma_{2}$ is $50 \mathrm{MPa}$ and $60 \mathrm{MPa}$, which indicates that the ability to bear lateral deformation significantly decreases due to damage from confining pressure. The latter decreases slightly when $\sigma_{2}$ is $60 \mathrm{MPa}$, which indicates that the damage caused by confining pressure could be significantly weakened due to an increase in $\sigma_{3}$. The volumetric strain increment is similar to that in the direction of $\sigma_{3}$.

\section{AE Behavior}

$\mathrm{AE}$ is a phenomenon that microcracks generate during crack development, which is accompanied by the release of an elastic wave or stress wave. Deformation and failure of the 


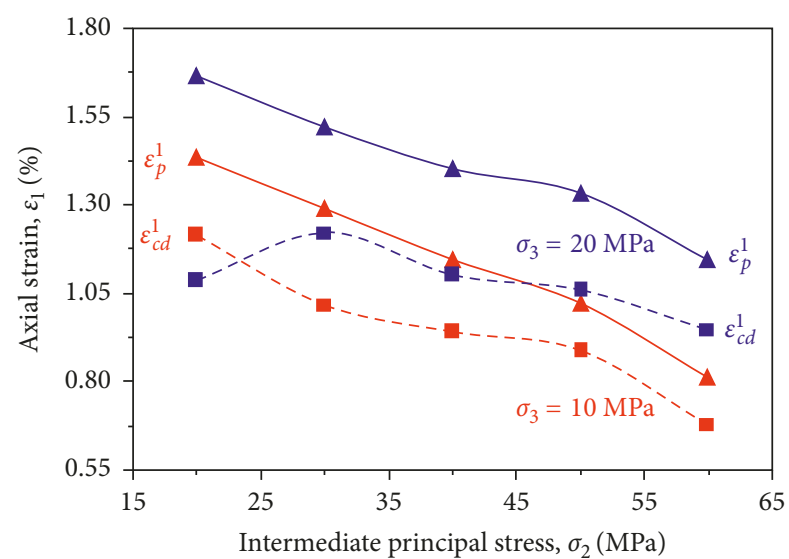

(a)

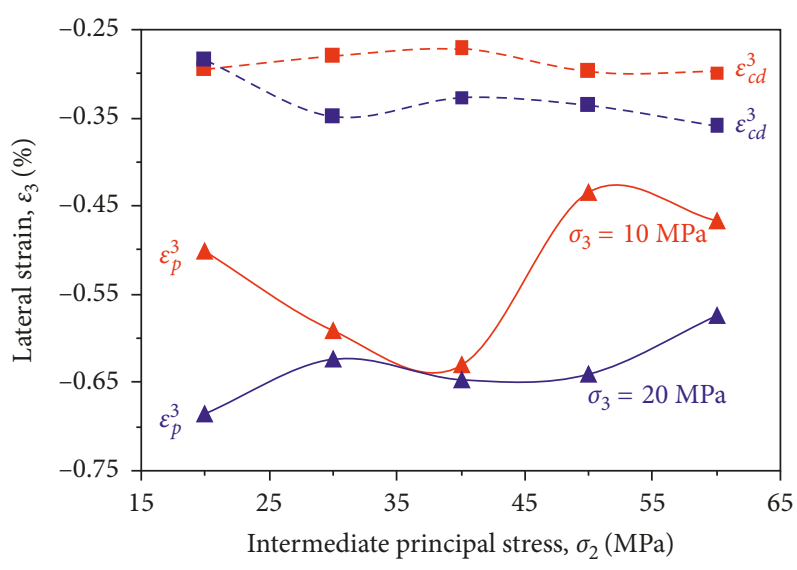

(c)

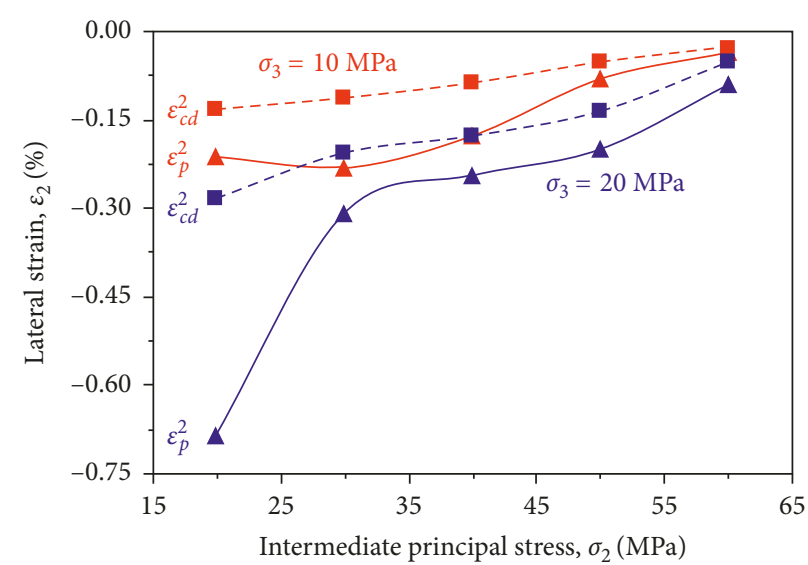

(b)

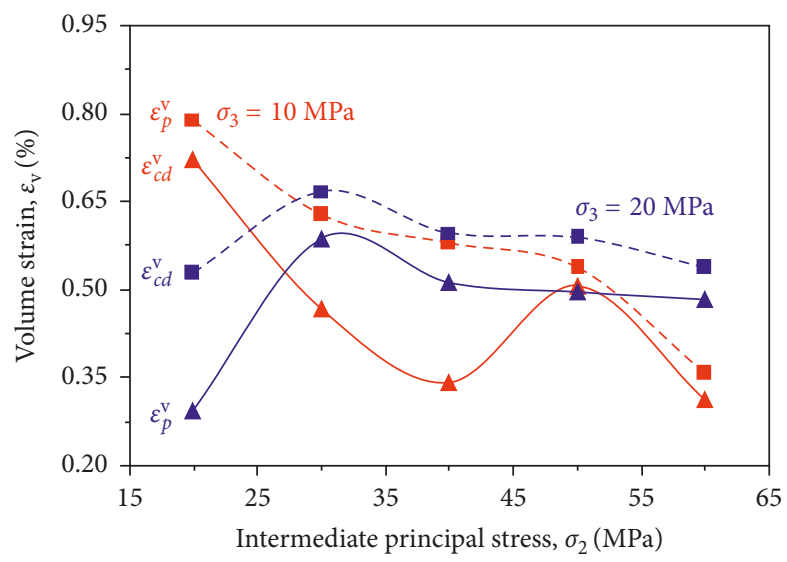

(d)

FIGURE 12: Strain characteristics of rock damage point and peak point under true triaxial compression: (a) axial strain; (b) lateral strain (the intermediate principal stress direction); (c) lateral strain (the minimum principal stress direction); (d) volumetric strain.

rock are accompanied by the generation of the $\mathrm{AE}$. $\mathrm{AE}$ information contains precursor information for rock failure. The AE information during compression and failure of the rock is used to predict the rock failure process, which is of great importance to monitoring deformation in mines and other geotechnical engineering [23].

The typical curve of the cumulative AE events with the change of strain under different loading conditions is shown in Figure 14. The characteristics of the rock in unstable crack growth stage (the same below) are only selected in this study. $\mathrm{AE}$ events increase sharply in this stage, and interactions among cracks increase. AE events weaken gradually with increasing confining pressure under conventional triaxial compression, and the cumulative $\mathrm{AE}$ counts decrease gradually when the peak value is reached. With a confining pressure of $10 \mathrm{MPa}$, the cumulative $\mathrm{AE}$ counts are significantly higher than the one with higher confining pressure. Since the constraint on lateral deformation with low confining pressure under conventional triaxial compression is small, it is easy to produce new microcracks and generate slip along cracks, creating a more active acoustic emission signal. High confining pressure reduces the generation of internal fractures and shear slip, producing relatively low $\mathrm{AE}$ counts. The higher the confining pressure, the stronger the binding effect is, which enhances the rock's capacity to withstand deformation and loading.

$\mathrm{AE}$ count decreases first and then increases under true triaxial compression. When $\sigma_{3}$ is $10 \mathrm{MPa}, \mathrm{AE}$ events increase with increasing $\sigma_{2}$ (Figure 14(b)). When $\sigma_{2}$ is $20 \sim 40 \mathrm{MPa}$, the cumulative $\mathrm{AE}$ counts gradually reduce with increasing $\sigma_{2}$. There is no "sudden increase" phenomenon, and the rock produces many continuous $\mathrm{AE}$ counts. In combination with the AE characteristics under conventional triaxial compression, numerous shear slip cracks are produced in this stage (which would be analyzed in detail below), and microcracks converge and perforate within the rock, leading to the formation of macroshear and slip surfaces. When $\sigma_{2}$ is 50 and $60 \mathrm{MPa}$, the cumulative $\mathrm{AE}$ counts increase rapidly, and there is a "sudden increase" phenomenon indicating that the increase of $\sigma_{2}$ inhibits the deformation in the $\sigma_{2}$ direction but promotes the lateral expansion in the $\sigma_{3}$ direction. The rock produces many tensile cracks whose convergence and perforation cause fracture surfaces to form. The confining pressure gradually evolves from a constraining force to a damaging force, greatly weakening the carrying capacity of the rock. When $\sigma_{3}$ is $20 \mathrm{MPa}, \mathrm{AE}$ events change slightly with increasing $\sigma_{2}$. Here, when $\sigma_{2}$ is $30 \sim 50 \mathrm{MPa}$, the 


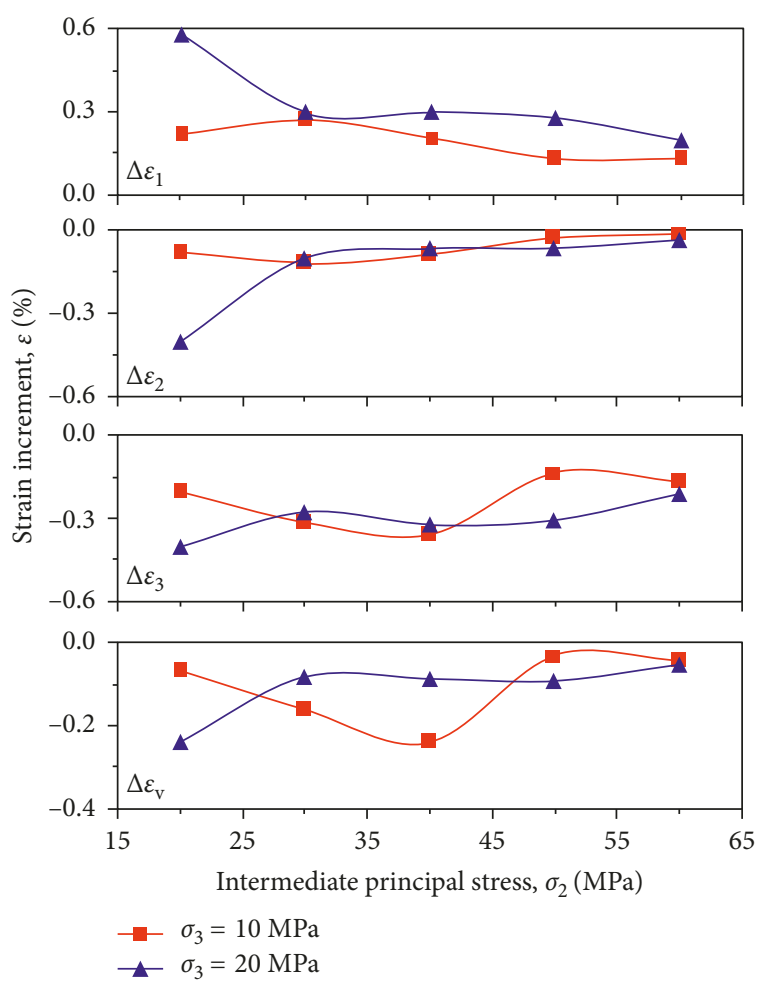

FIGURE 13: Variation in strain increment of rock in the unstable crack growth stage under true triaxial compression.

typical AE event curves (Figure 14(c)) are similar to each other, and more shear and slip cracks are formed. The constraining effect of confining pressure to internal cracks is enhanced, and the development of cracks is suppressed by increasing $\sigma_{2}$. When $\sigma_{2}$ is $60 \mathrm{MPa}$, the cumulative $\mathrm{AE}$ counts increase rapidly, but there is no "sudden increase" phenomenon, indicating that the confining pressure damages the rock and promotes the development of rock cracks. For $\sigma_{3}=10 \mathrm{MPa}$, the damage effect is greatly weakened by improving $\sigma_{3}$ and the rock is protected.

In order to further analyze the destruction of sandstone under different loading conditions, the value of RA (the ratio of the rise time and the amplitude) and the average frequency value $\mathrm{AF}$ (the ratio of the ringing count and the duration) of the $\mathrm{AE}$ parameters are used to describe the type of microcracks within the rock. In general, AE signals with low AF and high RA or with high AF and low RA usually represent the generation or development of shear or tensile cracks, respectively [24-26]. Energy levels are combined to analyze the distribution law for RA under three kinds of $\mathrm{AE}$ levels which are $0.1 \sim 1,1 \sim 10$, and $>10 \mathrm{mV}^{2} \cdot \mathrm{ms}$ (ignore $<0.1$ ) (Figure 15). Microcracks in the rock under the three loading conditions are stretched and expanded. The AE count which has an AE energy of over $10 \mathrm{mV}^{2} \cdot \mathrm{ms}, 1 \sim 10 \mathrm{mV}^{2} \cdot \mathrm{ms}$, and $0.1 \sim 1 \mathrm{mV}^{2} \cdot \mathrm{ms}$ is small, large, and dense. According to the energy level, the proportion rule of the rock shear cracks under different loading conditions is shown in Figure 16.

The proportion of the shear cracks under conventional triaxial compression with $\mathrm{AE}$ energy greater than $10 \mathrm{mV}^{2} \cdot \mathrm{ms}$ varied little with increasing confining pressure, which is in

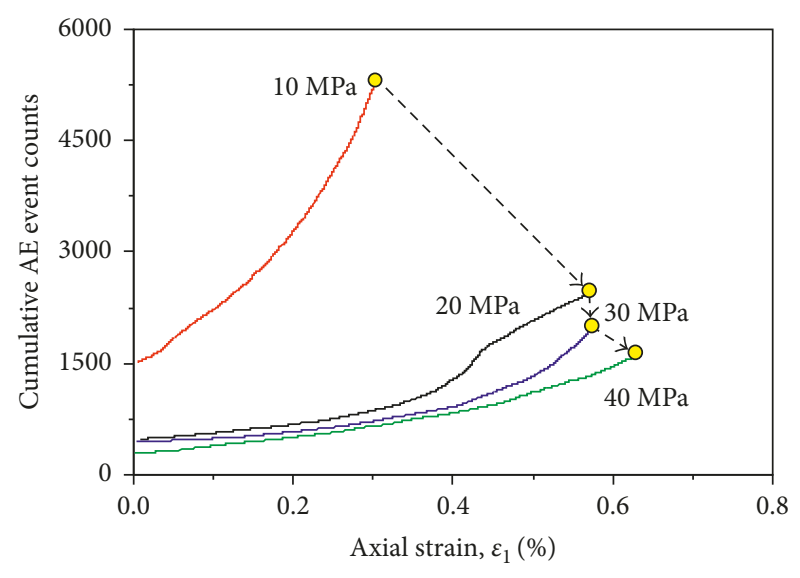

(a)

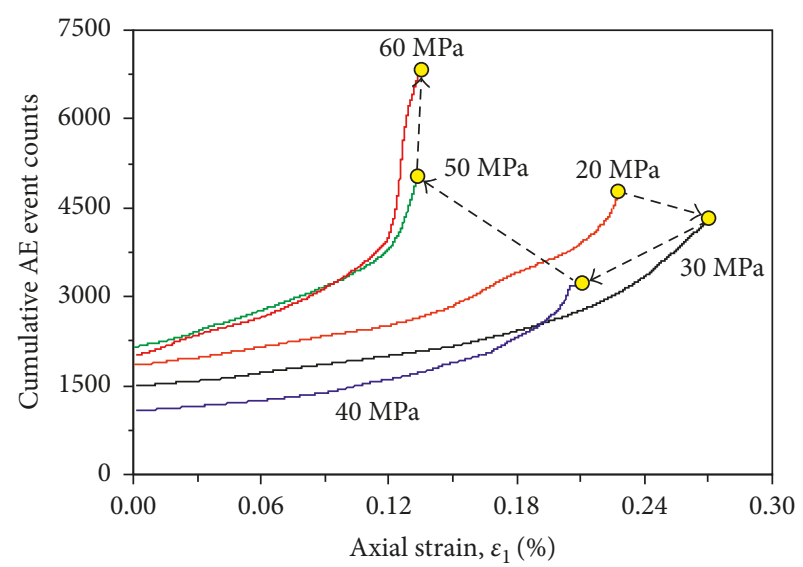

(b)

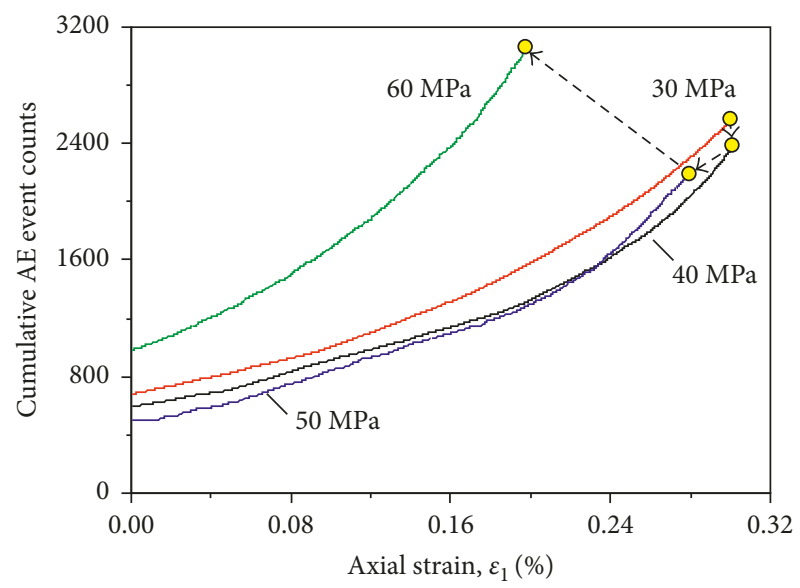

(c)

FIgURE 14: The typical curve of the cumulative number of $\mathrm{AE}$ events with the change in strain under different loading conditions: (a) CTT; (b) TTT $\left(\sigma_{3}=10 \mathrm{MPa}\right)$; (c) TTT $\left(\sigma_{3}=20 \mathrm{MPa}\right)$.

27\% 32\%. The proportion of shear cracks gradually increases (from $25 \%$ to $37 \%$ ) with $\mathrm{AE}$ energy from 1 to $10 \mathrm{mV}^{2} \cdot \mathrm{ms}$. The proportion of the shear cracks is relatively small and irregular with $\mathrm{AE}$ energy varying from 0.1 to $1 \mathrm{mV}^{2} \cdot \mathrm{ms}$ (only $\mathrm{AE}$ of more than $1 \mathrm{mV}^{2} \cdot \mathrm{ms}$ would be analyzed in the following paper). Although a former study believed that the rock sample 

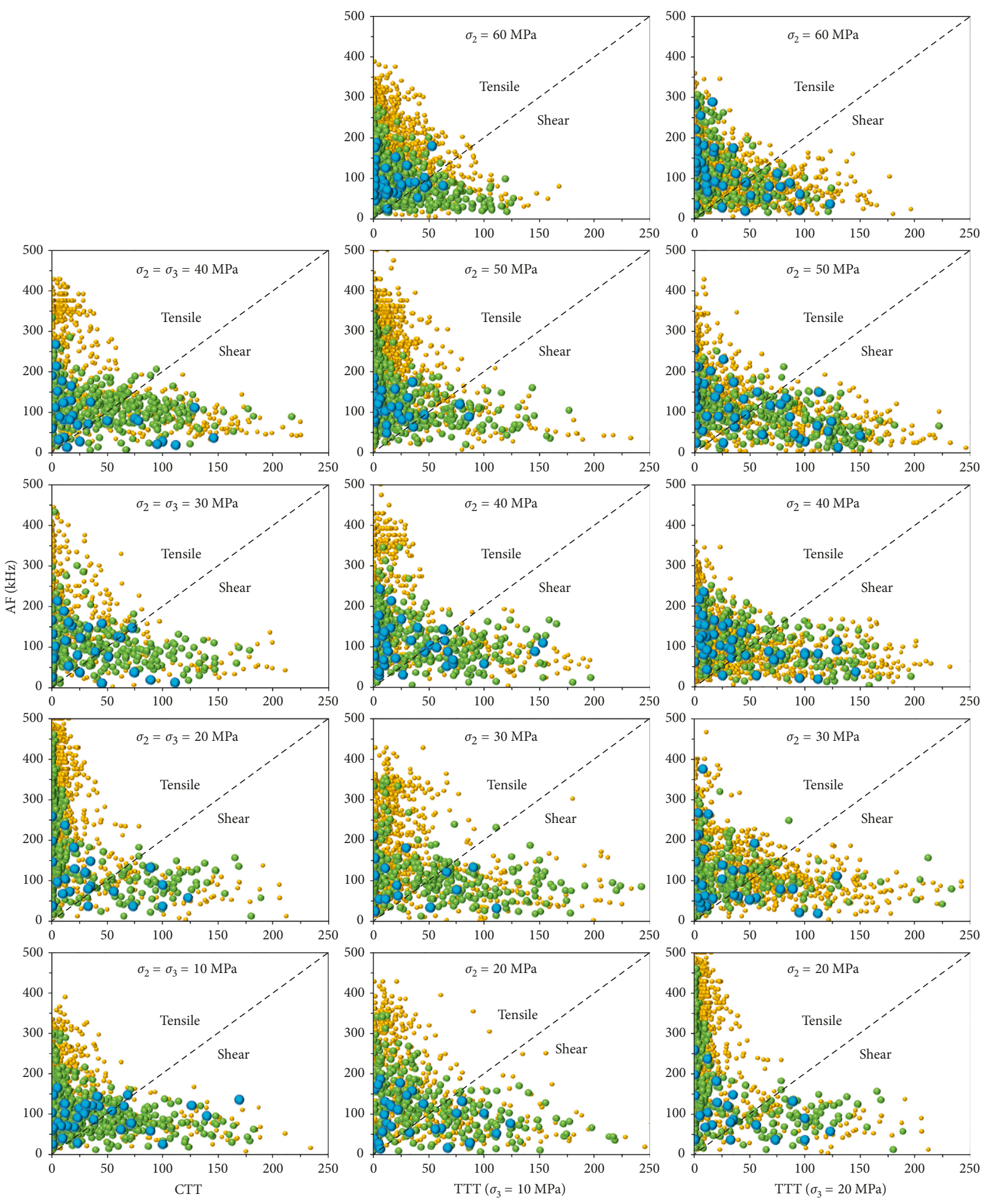

$0.1 \sim 1 \mathrm{mV}^{2} \cdot \mathrm{ms}$

- $1 \sim 10 \mathrm{mV}^{2} \cdot \mathrm{ms}$

- $>10 \mathrm{mV}^{2} \cdot \mathrm{ms}$

FIgURE 15: Variation of the RA and AF values under different loading conditions. 


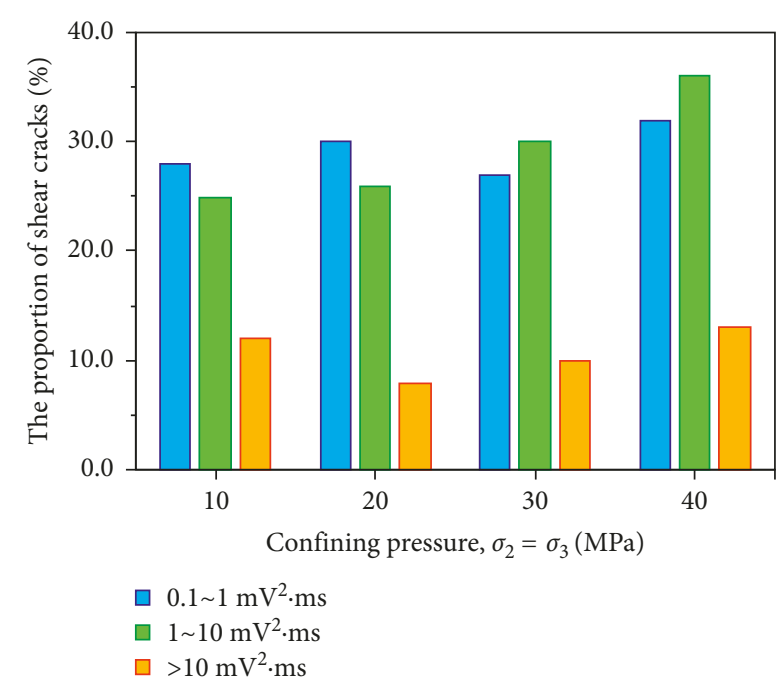

(a)

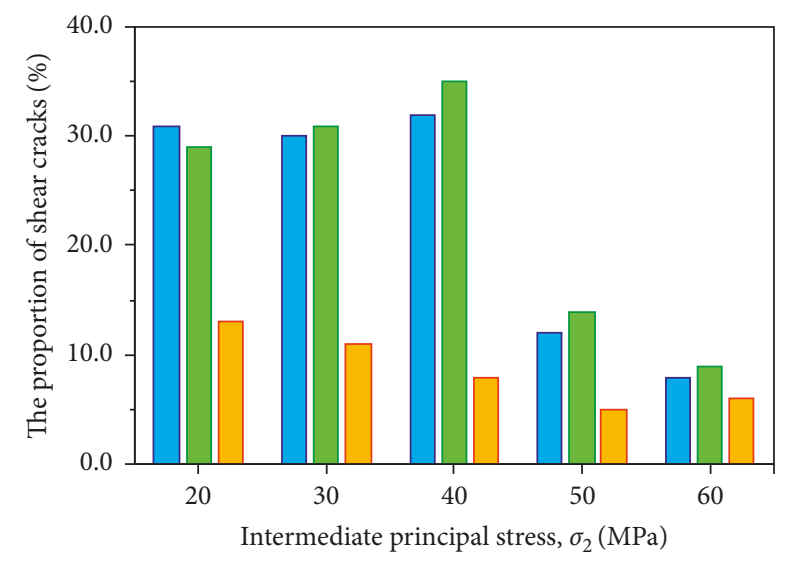

(b)

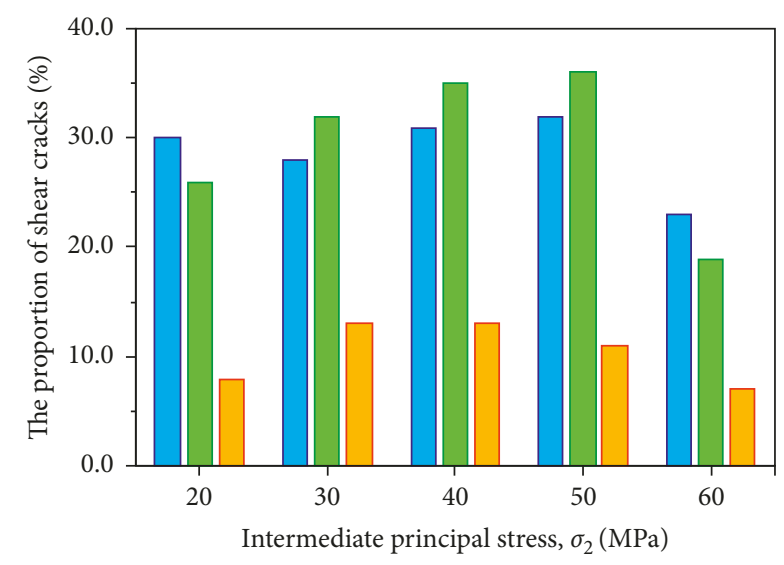

(c)

FIgURE 16: Proportion characteristics of shear cracks under different loading conditions: (a) CTT; (b) TTT $\left(\sigma_{3}=10 \mathrm{MPa}\right)$; (c) TTT $\left(\sigma_{3}=20 \mathrm{MPa}\right)$.

reflects the shear failure characteristics under conventional triaxial compression at the macrolevel, analyses in this study show that the macroshear failure of the rock samples at the microlevel is caused by tension, expansion, or a large number of connecting internal microcracks. The presence of shear cracks is often accompanied by a large number of tensile cracks, which is consistent with the existing literature $[27,28]$. The cracks need to overcome the confining pressure. The law of the proportion of shear cracks in which $\mathrm{AE}$ is over $1 \mathrm{mV}^{2} \cdot \mathrm{ms}$ increases with increasing confining pressure indicates that cracks gradually overcame the shear constraints of confining pressure. On the contrary, the shear slip is gradually inhibited due to increasing confining pressure and delaying penetration of the cracks and rupture of the rock surface, in affecting playing a protective role in rock.

There are significant differences in the change laws for RA under true triaxial compression in which $\sigma_{3}$ is 10 and $20 \mathrm{MPa}$. When $\sigma_{2}$ is $20 \sim 40 \mathrm{MPa}$, the former $\left(\sigma_{3}=10 \mathrm{MPa}\right)$ proportion of the shear cracks gradually increases (from $28 \%$ to $35 \%)$ with increasing $\Delta \varepsilon_{3}$ with $\mathrm{AE}$ energy greater than $1 \Delta \varepsilon_{\mathrm{v}}$. The role of confining pressure is similar to conventional triaxial compression. Slippage of rock cracks can effectively be inhibited by increasing $\sigma_{2}$, which delays the formation of macroshear and slip surfaces and plays a protective role in the rock. When $\sigma_{2}$ is 50 and $60 \mathrm{MPa}$, the proportion of shear cracks decreases dramatically $(12 \%$ and $9 \%$ resp.) with its $\mathrm{AE}$ energy more than $1 \mathrm{mV}^{2} \cdot \mathrm{ms}$, indicating that the rock records mainly tension and expansion, accompanied by a small amount of shear cracks. Tension cracks within the rock are constantly fused, and the macroscopic tension and failure surface instantaneously forms, which explains why the cumulative AE counts appeared as a "sudden increase" (Figure 14(b)). The effect of confining pressure on the cracks within the rock gradually evolves from a constraining force to a damage force. The latter $\left(\sigma_{3}=10 \mathrm{MPa}\right)$ has a relatively smooth change in RA. When $\sigma_{2}$ is $20 \sim 50 \mathrm{MPa}$, the proportion of the shear cracks gradually increases (from $26 \%$ to $37 \%$ ) with increasing $\sigma_{2}$ with $\mathrm{AE}$ energy of more than $1 \mathrm{mV}^{2} \cdot \mathrm{ms}$. By comparing with $\sigma_{3}=10 \mathrm{MPa}$, the proportion of shear cracks increases, indicating that the slip effect may be inhibited by increasing $\sigma_{3}$ and the rock is restricted laterally. When $\sigma_{2}$ is $60 \mathrm{MPa}$, the proportion of shear cracks (20\%) in which AE energy is more than $1 \mathrm{mV}^{2} \cdot \mathrm{ms}$ decreases. It is significantly larger than the former proportion with conditions the same as $\sigma_{2}$, indicating that the damage effect of confining pressure is weakened because of increasing $\sigma_{3}$, although the rock is damaged by the confining pressure, to some extent, which led to the increase of the tensional cracks of the rock.

\section{Conclusion}

In this study, the conventional triaxial and true triaxial tests of sandstone under different stress states are carried out using the self-developed true triaxial electrohydraulic servo test system. Deformation, strength, AE characteristic parameters, and development of the internal cracks are studied under different confining pressures, intermediate principal stresses, and minimum principal stresses. The primary research results are summarized as follows:

(1) The strength of the sandstone increases with increasing confining pressure under conventional 
triaxial compression, while the strength of sandstone increases first and then decreases with increasing intermediate principal stress under true triaxial compression. The strength under the true triaxial condition is consistent with the Mogi-Coulomb criterion. The rock is protected obviously, and the peak strength of the rock is greatly improved by increasing $\sigma_{3}$.

(2) The deformation characteristics of the rock under the two loading conditions are quite different. Under conventional triaxial compression, the axial strain and lateral strain as well as the elastic modulus increase with increasing confining pressure before failure, showing that the ability of the rock to withstand deformation capacity of the rock is gradually improved because of the increase in confining pressure under conventional triaxial compression. Under true triaxial compression $\left(\sigma_{3}\right.$ equal $\left.10,20 \mathrm{MPa}\right)$, the elastic modulus of the rock first increases and then decreases, and the axial strain $\varepsilon_{1}$ and lateral strain $\varepsilon_{2}$ decrease gradually with increasing $\sigma_{2}$. The lateral strain (swelling) of the rock is mainly along the $\sigma_{3}$ direction, and the tendency of the lateral expansion is to decrease first and then to increase. In the unstable crack growth stage, the lateral strain $\varepsilon_{p}^{3}$ and strain increment $\Delta \varepsilon_{3}, \Delta \varepsilon_{\mathrm{V}}$ first increase and then decrease, but the former appears as "cliff" decrease when $\sigma_{2}$ is 50 and $60 \mathrm{MPa}$, while the latter decreases slightly when $\sigma_{2}$ is $60 \mathrm{MPa}$. The variation of strain increment $\Delta \varepsilon_{3}, \Delta \varepsilon_{\mathrm{V}}$ in the stage is similar, indicating that when $\sigma_{2}$ is large, the former ability to bear lateral deformation is weakened significantly, while the latter can greatly reduce the role of confining pressure damage at this time and provide a protective effect to the rock due to increasing $\sigma_{3}$.

(3) In this study, the AE characteristics of rocks in unstable crack growth stage under conventional and true triaxial compression are analyzed. It is found that microcracks in the sandstone reflected mainly stretching and expansion under the two loading conditions (the characteristics of AE signals are high $\mathrm{AF}$ and low RA); however, the AE characteristics are significantly different. The trend of AE activity for rocks under conventional triaxial compression is "gradually reduced" with increasing confining pressure, and the shear and slip effect of the cracks is gradually inhibited. AE events first weaken and then enhance with increasing $\sigma_{2}$ under true triaxial compression in which $\sigma_{3}$ is 10 and $20 \mathrm{MPa}$. When the former $\sigma_{2}$ is $20 \sim 40 \mathrm{MPa}$, the cumulative AE counts gradually decrease with increasing $\sigma_{2}$, and the proportion of the shear cracks increases gradually. When $\sigma_{2}$ is 50 and $60 \mathrm{MPa}$, the cumulative AE counts increases rapidly, and there is a "sudden increase" phenomenon. The proportion of the shear cracks decreases dramatically, showing that the confining pressure gradually evolves from the shear and slip effect inhibiting shear cracks to damage the rock promoting the formation of tensional cracks with increasing $\sigma_{2}$, resulting in an instant of macrotension rupture formation. But, the damage of confining pressure is weakened by increasing $\sigma_{3}$ (the latter $\left.\sigma_{3}=20 \mathrm{MPa}\right)$.

\section{Conflicts of Interest}

The authors declare that they have no conflicts of interest.

\section{Acknowledgments}

The authors gratefully acknowledge the support provided by the National Basic Research Program of China (Grant no. 2014CB046905), the National Natural Science Foundation of China (NSFC) (Grant no. 51404245), and the China Postdoctoral Science Foundation Funded Project (Grant nos. 2014M551699 and 2016T90527).

\section{References}

[1] H. Moomivand, "Effects of orientation, frequency, and number of sets of discontinuities on rock strength under triaxial stresses," Arabian Journal of Geosciences, vol. 7, no. 12, pp. 5345-5352, 2014.

[2] T. V. Karman, "Festigkeitsversuche unter allseitigem druck," Mitteilungen Forschungsarbeit Gebiete Ingenieurs, vol. 55, pp. 1749-1759, 1911.

[3] J. T. Fredrich, B. Evans, and T. F. Wong, "Effect of grain size on brittle and semibrittle strength: implications for micromechanical modelling of failure in compression," Journal of Geophysical Research Solid Earth, vol. 95, no. B7, pp. 1090710920, 1990.

[4] S. Q. Yang, H. W. Jing, and S. Y. Wang, "Experimental investigation on the strength, deformability, failure behavior and acoustic emission locations of red sandstone under triaxial compression," Rock Mechanics and Rock Engineering, vol. 45, no. 4, pp. 583-606, 2012.

[5] K. Mogi, "Fracture and flow of rocks under high triaxial compression," Journal of Geophysical Research Atmospheres, vol. 76, no. 5, pp. 1255-1269, 1971.

[6] K. Mogi, "Flow and fracture of rocks under general triaxial compression," Applied Mathematics and Mechanics, vol. 6, no. 2, pp. 635-651, 1981.

[7] B. Haimson and C. Chang, "A new true triaxial cell for testing mechanical properties of rock, and its use to determine rock strength and deformability of Westerly granite," International Journal of Rock Mechanics and Mining Sciences, vol. 37, no. 1, pp. 285-296, 2000.

[8] B. Haimson, "True triaxial stresses and the brittle fracture of rock," Pure and Applied Geophysics, vol. 163, no. 5-6, pp. 1101-1130, 2006.

[9] X. T. Feng, X. Zhang, R. Kong, and G. Wang, "A Novel Mogi type true triaxial testing apparatus and its use to obtain complete stress-strain curves of hard rocks," Rock Mechanics and Rock Engineering, vol. 49, no. 5, pp. 1-14, 2015.

[10] T. Sriapai, C. Walsri, and K. Fuenkajorn, "True-triaxial compressive strength of Maha Sarakham salt," International Journal of Rock Mechanics and Mining Sciences, vol. 61, no. 10, pp. 256-265, 2013.

[11] M. You, "True-triaxial strength criteria for rock," International Journal of Rock Mechanics and Mining Sciences, vol. 46, no. 1, pp. 115-127, 2009. 
[12] X. Ma, J. W. Rudnicki, and B. C. Haimson, "The application of a Matsuoka-Nakai-Lade-Duncan failure criterion to two porous sandstones," International Journal of Rock Mechanics and Mining Sciences, vol. 92, pp. 9-18, 2017.

[13] Z. A. Moradian, G. Ballivy, P. Rivard, C. Gravel, and B. Rousseau, "Evaluating damage during shear tests of rock joints using acoustic emissions," International Journal of Rock Mechanics and Mining Sciences, vol. 47, no. 4, pp. 590-598, 2010.

[14] S. Q. Yang, H. M. Ni, and S. Wen, "Spatial acoustic emission evolution of red sandstone during multi-stage triaxial deformation," Journal of Central South University, vol. 21, no. 8, pp. 3316-3326, 2014.

[15] V. Vishal, P. G. Ranjith, and T. N. Singh, "An experimental investigation on behaviour of coal under fluid saturation, using acoustic emission," Journal of Natural Gas Science and Engineering, vol. 22, pp. 428-436, 2015.

[16] J. Yin, C. Cheng, M. Kumruzzaman, and W. Zhou, "New mixed boundary, true triaxial loading device for testing threedimensional stress-strain-strength behaviour of geomaterials," Canadian Geotechnical Journal, vol. 47, no. 1, pp. 1-15, 2010.

[17] J. F. Labuz and J. M. Bridell, "Reducing frictional constraint in compression testing through lubrication," International Journal of Rock Mechanics and Mining Science, vol. 30, no. 4, pp. 451-455, 1993.

[18] A. M. Al-Ajmi and R. W. Zimmerman, "Relation between the Mogi and the Coulomb failure criteria," International Journal of Rock Mechanics and Mining Sciences, vol. 42, no. 3, pp. 431-439, 2005.

[19] H. Oku, B. Haimson, and S. R. Song, "True triaxial strength and deformability of the siltstone overlying the Chelungpu fault (Chi-Chi earthquake), Taiwan," Geophysical Research Letters, vol. 34, no. 9, pp. 139-158, 2007.

[20] H. Lee and B. C. Haimson, "True triaxial strength, deformability, and brittle failure of granodiorite from the San Andreas Fault Observatory at depth," International Journal of Rock Mechanics and Mining Sciences, vol. 48, no. 7, pp. 1199-1207, 2011.

[21] C. Chang and B. Haimson, "A failure criterion for rocks based on true triaxial testing," Rock Mechanics and Rock Engineering, vol. 45, no. 6, pp. 1007-1010, 2012.

[22] C. D. Martin and N. A. Chandler, "The progressive fracture of Lac du Bonnet granite," International Journal of Rock Mechanics and Mining Science, vol. 31, no. 6, pp. 643-659, 1994.

[23] X. Kong, E. Wang, S. Hu, R. Shen, X. Li, and T. Zhan, "Fractal characteristics and acoustic emission of coal containing methane in triaxial compression failure," Journal of Applied Geophysics, vol. 124, pp. 139-147, 2016.

[24] D. G. Aggelis, E. Z. Kordatos, and T. E. Matikas, "Acoustic emission for fatigue damage characterization in metal plates," Mechanics Research Communications, vol. 38, no. 2, pp. 106-110, 2011.

[25] S. Shahidan, R. Pulin, N. M. Bunnori, and K. M. Holford, "Damage classification in reinforced concrete beam by acoustic emission signal analysis," Construction and Building Materials, vol. 45, no. 13, pp. 78-86, 2013.

[26] E. Tsangouri, D. Aggelis, T. Matikas, and A. Mpalaskas, "Acoustic emission activity for characterizing fracture of marble under bending," Applied Sciences, vol. 6, no. 1, p. 6, 2015.

[27] K. B. Broberg, "On crack paths," Engineering Fracture Mechanics, vol. 28, no. 5-6, pp. 663-679, 1987.

[28] Y. L. Lu, D. Elsworth, and L. G. Wang, "Microcrack-based coupled damage and flow modeling of fracturing evolution in permeable brittle rocks," Computers and Geotechnics, vol. 49, no. 4, pp. 226-244, 2013. 


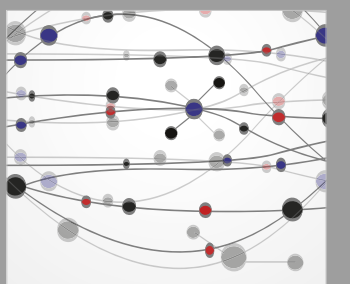

The Scientific World Journal
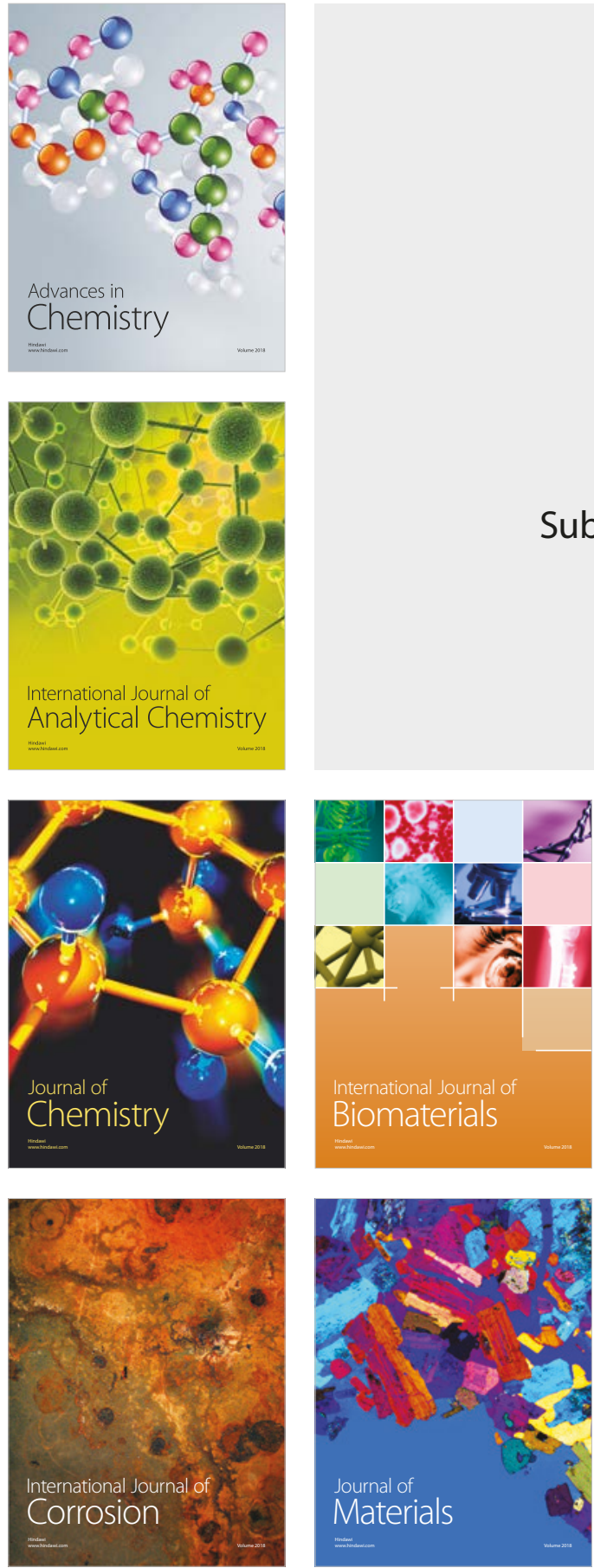

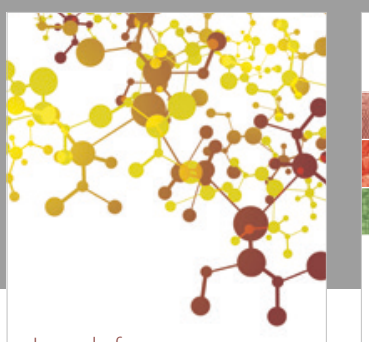

Journal of

Applied Chemistry
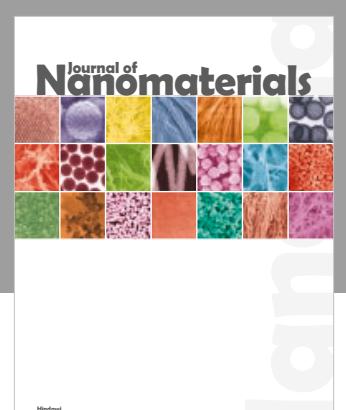

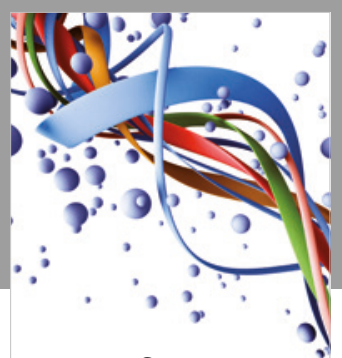

Scientifica

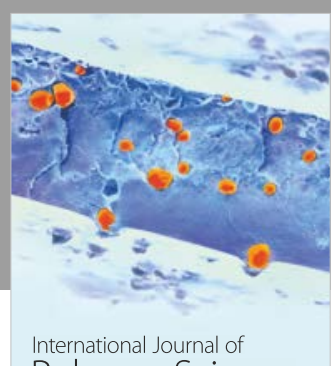

Polymer Science

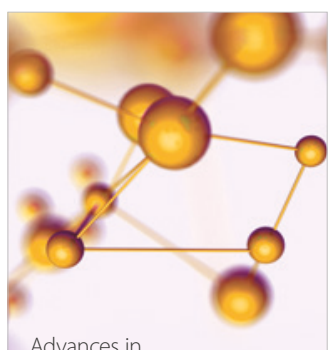

Physical Chemistry
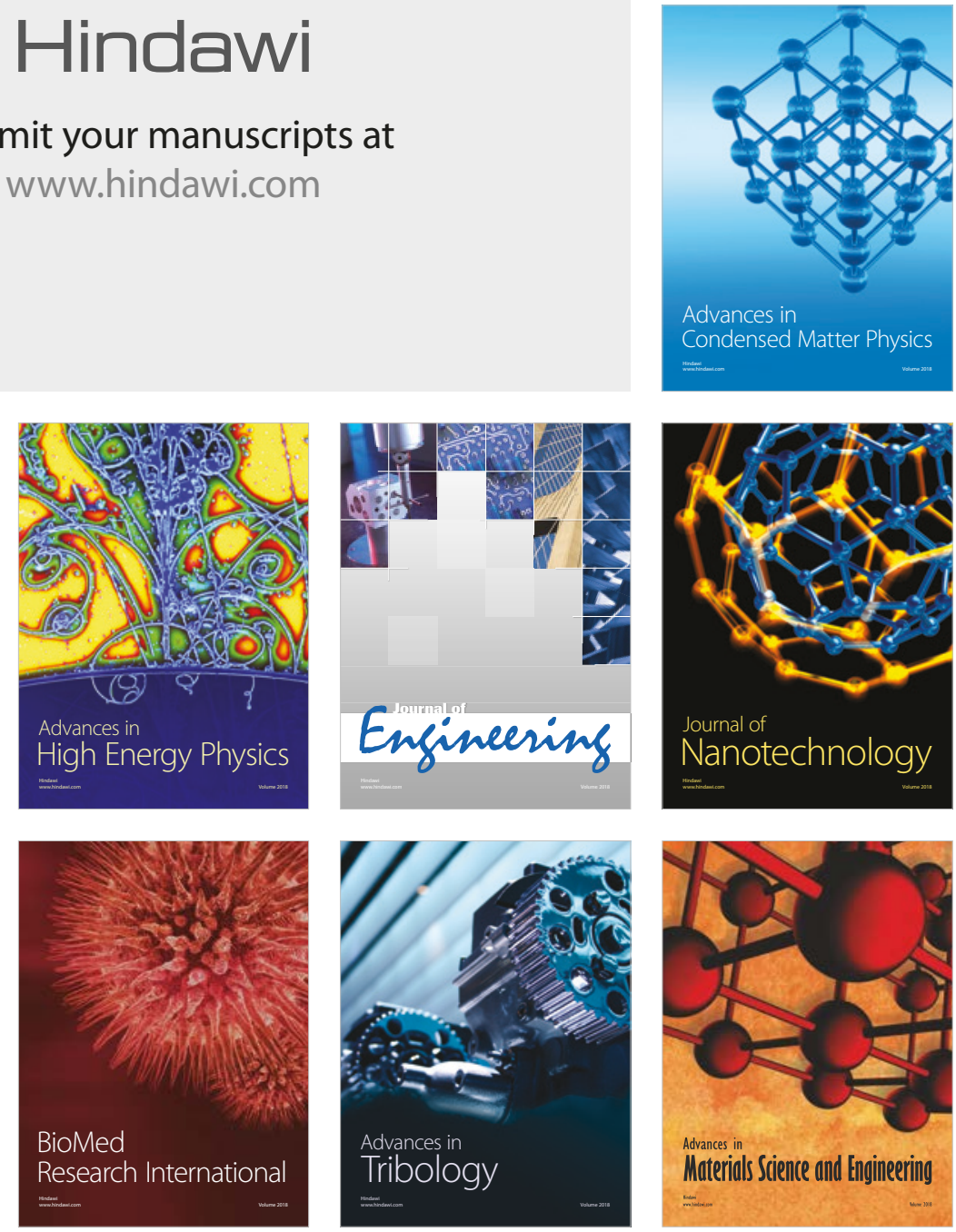